\title{
Synthesis, DFT calculations, photophysical, photochemical properties of peripherally metallophthalocyanines bearing (2-(benzo[d] [1,3] dioxol-5-ylmethoxy) phenoxy) substituents
}

\section{Derya Güngördü Solğun}

Van Yuzuncu Yil University: Van Yuzuncu Yil Universitesi

Ümit Yıldıko

Kafkas University: Kafkas Universitesi

Mehmet Salih Ağırtaş ( $\square$ salihagirtas@hotmail.com )

Van Yuzuncu Yıl University https://orcid.org/0000-0003-1296-2066

\section{Research Article}

Keywords: Fluorescence, DFT, Phthalocyanine, Aggregation, the docking study

Posted Date: April 13th, 2021

DOI: https://doi.org/10.21203/rs.3.rs-393739/v1

License: (c) (1) This work is licensed under a Creative Commons Attribution 4.0 International License.

Read Full License 


\section{Abstract}

4-(2-(benzo[d] [1, 3] dioxol-5-ylmethoxy) phenoxy) phthalonitrile was first prepared as a starting material. Then, this new phthalonitrile derivative was reacted with $\mathrm{Zn}$ and Co salts to obtain new phthalocyanine complexes. Phthalocyanine complexes were evaluated by fluorescence emission, extinction, and absorption measurements. Aggregation studies show the compliance with the lambert-beer law in the concentration range studied for peripheral phthalocyanine compounds. The density functional theory (DFT) calculations of the metallophthalocyanines compounds were performed using B3LYP / 6-31G in Zn-Pc and B3LYP / LanL2DZ in Co-Pc to derive structural optimization, HOMO-LUMO energy parameters, and NLO properties. The calculated values of M-Pcs with different center atoms were obtained close to each other. Molecular electronic surface (MEP) maps of the studied compounds are mapped and discussed. The HOMO-LUMO energy gaps of our compounds studied are around $2.1 \mathrm{eV}$. The docking studies were performed with the phthalonitrile.

\section{Introduction}

Phthalocyanines have been a subject of interest for research for nearly a century. Promising results have been achieved in many areas. It is produced and used for fifty tons of paint industry worldwide[1, 2]. Besides, it is used in many fields such as catalyst[3], sensor[4, 5], liquid crystal[6], optical data storage[7, 8], solar cells[9]. Photodynamic therapy, which is one of the cancer treatment methods, is being researched as the subject of intensive research[10-12]. The synthesis of phthalocyanine compounds capable of producing appropriate singlet oxygen excites researchers. For this purpose, many scientific articles on phthalocyanines are published annually. Obtaining new functional and soluble phthalocyanines from these publications is seen as an important objective[13, 14]. Phthalocyanines are used to produce new and functional materials to meet today's needs. New substitute groups are formed by connecting to the peripheral and non-peripheral or axial positions of the phthalocyanines[15]. One of the main goals of phthalocyanine chemistry is to provide the use of this compound in photodynamic therapy for sensor and therapeutic purposes[16]. In addition to the research of the present compounds, there is a need for alternative studies with the synthesis of new phthalocyanine compounds.

In this study, 4-(2-(benzo[d] [1, 3] dioxol-5-ylmethoxy) phenoxy) phthalonitrile compound was prepared as a starting material with a new design. Phthalocyanine complexes were synthesized from the reaction of this compound with zinc and cobalt salts under suitable conditions. The characterization of the obtained compounds, as well as aggregation, solubility, electronic absorption, fluorescence spectra, and computational properties, have been investigated. The synthesized phthalonitrile molecule also complied with the drug similarity rules and displayed acceptable predicted ADME properties.

\section{Experimental}

An electrothermal device was used to determine the melting point. Electronic transitions for the complexes were measured with a Hitachi U-2900 Spectrophotometer. FT-IR vibrations were determined by 
Thermo Scientific FT-IR spectrophotometer. The masses of the compounds were determined by the LCMS TOF electrospray ionization technique. ${ }^{1} \mathrm{H}$ and ${ }^{13} \mathrm{C}$ NMR spectra were measured with an Agilent 400 $\mathrm{MHz}$ spectrometer. Fluorescence emission measurements were made in a shımadzu RF-6000 spectrofluorophotometer. Chemicals and solvents were used commercially without purification.

\section{4-(2-(benzo[d] [1, 3] dioxol-5-ylmethoxy) phenoxy) phthalonitrile (4)}

2-nitrophenol 1 (0.402 g, $2.89 \mathrm{mmol})$ and 4-nitrophthalonitrile $2(0.500 \mathrm{~g}, 2.89 \mathrm{mmol})$ in $25 \mathrm{~mL}$ dimethylformamide (DMF) was stirred at room temperature under nitrogen atmosphere. After stirring for $30 \mathrm{~min}$, piperonyl alcohol $3(0.439 \mathrm{~g}, 2.89 \mathrm{mmol})$ was added into the mixture. After stirring for $15 \mathrm{~min}$, $\mathrm{K}_{2} \mathrm{CO}_{3}(2.2 \mathrm{~g}, 15.94 \mathrm{mmol})$ was added into the mixture over a period of $2 \mathrm{~h}$. The reaction mixture was further stirred for $42 \mathrm{~h}$ at room temperature. The reaction mixture was poured into cold water (ics) (150

$\mathrm{mL}$ ) and stirred. The precipitate was filtered off, washed with water to neutralize it, the product was dried in a vacuum oven at $80^{\circ} \mathrm{C}$. MP: $153-156^{\circ} \mathrm{C}$. Yield: $0.740 \mathrm{gr}$. The product is soluble in $\mathrm{CHCl}_{3}, \mathrm{CH}_{2} \mathrm{Cl}_{2}$, acetonitrile, ethyl acetate, THF, DMF, DMSO. IR spectrum $\left(\mathrm{cm}^{-1}\right)$ : 3086, 2926, 2233, 1602, 1564, 1500, $1448,1284,1249,1172,1095,1033,925$. HRMS (ESI); $(\mathrm{M}+\mathrm{H})$ calc. for $\mathrm{C}_{22} \mathrm{H}_{14} \mathrm{~N}_{2} \mathrm{O}_{4}$ : 370.36; found: $393.08\left[\mathrm{M}+\mathrm{Na}^{+}\right.$. ${ }^{1} \mathrm{H}$ NMR $\left(400 \mathrm{MHz}, \mathrm{DMSO}_{6} \mathrm{~d}_{6}\right):(\delta: \mathrm{ppm})$ 8.18, 8.09, 8.06, 8.03, 7.81, 7.53, 7.01, 6.93, $6.01,5.14,3.30,2.49 .{ }^{13} \mathrm{C}$ NMR (400 MHz, DMSO-d 6 ): (ס: ppm) 162.09, 147.90, 147.82, 136.77, 136.47, $136.21,129.51,122.69,120.94,116.68,116.63,116.15,109.27,108.67,106.50,101.59,70.92,40.63,40.42$, $40.22,40.01,39.80,39,59,39.38$.

$2,10,16,24$ - Tetrakis (2-(benzo[d] [1, 3] dioxol-5-ylmethoxy) phenoxy) phthalocyaninato) zinc (II) (5)

A mixture of 4-(2-(benzo[d] [1, 3] dioxol-5-ylmethoxy) phenoxy) phthalonitrile $4(0.050 \mathrm{~g}, 0.135 \mathrm{mmol})$ and $\mathrm{ZnCl}_{2}(0.015 \mathrm{~g})$ mixture was powdered in a quartz crucible and heated in a sealed glass tube for $5 \mathrm{~min}$ $210^{\circ} \mathrm{C}$ in the presence of DBU (2 drops). After reaching room temperature, the product was washed with hot and cold water, ethanol, methanol. The product soluble in THF was collected and the solvent was removed to obtain a green solid. This compound is soluble in dichloromethane, $\mathrm{CHCl}_{3}, \mathrm{THF}, \mathrm{DMF}, \mathrm{DMSO}$. Yield: $0.020 \mathrm{~g}\left(38.46 \%\right.$ ). UV-Vis (THF) $\lambda \max (\log \otimes): 676$ (5.08), 610(4.44), 348 (4.85). ${ }^{1} \mathrm{H}$ NMR (400 MHz, DMSO-d $)_{6}$ : ( $\left(\right.$ : ppm) 7.24, 7.06, 6.85, 6.07, 6.00, 5.54, 3.32, 2.48, 1.34. IR spectrum $\left(\mathrm{cm}^{-1}\right)$ : 3084, 2929, $2868,1643,1598,1487,1234,1159,1116,1085,1035,983$. HRMS (ESI); (M + H) calc. for $\mathrm{C}_{88} \mathrm{H}_{56} \mathrm{~N}_{8} \mathrm{O}_{16} \mathrm{Zn:}$ 1544.31; found: $1545.31[\mathrm{M}+\mathrm{H}]^{+}$.

2, 10, 16, 24 - Tetrakis (2-(benzo[d] [1, 3] dioxol-5-ylmethoxy) phenoxy) phthalocyaninato) cobalt(II) (6)

A mixture of 4-(2-(benzo[d] [1, 3] dioxol-5-ylmethoxy) phenoxy) phthalonitrile $3(0.050 \mathrm{~g}, 0.135 \mathrm{mmol})$ and $\mathrm{CoCl}_{2}(0.015 \mathrm{~g})$ mixture was powdered in a quartz crucible and heated in a sealed glass tube for $5 \mathrm{~min}$ $210{ }^{\circ} \mathrm{C}$. After reaching room temperature, the product was washed with hot and cold water, ethanol, methanol. The product soluble in THF was collected and the solvent was removed to obtain a green solid. 
This compound is soluble in ethanol, THF, DMF, DMSO. Yield: $0.035 \mathrm{~g}(67.37 \%)$. UV-Vis (THF) $\lambda \max (\log$ 邓): 668 (5.20). IR spectrum ( $\left.\mathrm{cm}^{-1}\right)$ : 3018, 2970, 1598, 1483, 1238, 1089, 1035, 920,837,734. HRMS (ESI); $(\mathrm{M}+\mathrm{H})$ calc. for $\mathrm{C}_{88} \mathrm{H}_{56} \mathrm{~N}_{8} \mathrm{O}_{16} \mathrm{Co:} 1539.31$; found: $1540.41[\mathrm{M}+\mathrm{H}]^{+}$.

\section{Results And Discussion}

Formulations of synthesized phthalocyanines and starting material are shown in Fig.1. 2-Nitrophenol, 4nitrophenol, and piperonyl alcohol as the stoichiometric was reacted under nitrogen in the dimethylformamide to form 4-(2-(benzo[d] [1,3] dioxol-5-ylmethoxy) phenoxy) phthalonitrile. Zinc and cobalt phthalocyanines were then synthesized from this starting material. The reaction of zinc chloride and cobalt chloride salts with 4-(2-(benzo[d] [1,3] dioxol-5-ylmethoxy) phenoxy) phthalonitrile at $210^{\circ} \mathrm{C}$ yielded zinc and cobalt phthalocyanines.

Spectral measurements of the compounds support the expected structure. Vibration of aromatic $\mathrm{C}-\mathrm{H}$ peak in the IR spectrum of compound number 4 is $3086 \mathrm{~cm}^{-1}, \mathrm{CH}_{2}$ vibration $2926 \mathrm{~cm}^{-1}, \mathrm{C} \equiv \mathrm{N}$ vibration $2233 \mathrm{~cm}^{-1}, \mathrm{Ar}-\mathrm{O}$ - Ar vibration $1249 \mathrm{~cm}^{-1}, \mathrm{C}=\mathrm{C}$ vibration peaks were observed at 1564 and $1500 \mathrm{~cm}^{-1}$. The vibration peaks observed here are compatible with the expected structure. The most prominent change is observed in nitrile peaks after the conversion of this compound to zinc and cobalt phthalocyanine compounds. The nitrile peak is expected to disappear completely. The nitrile peak observed in this study is also not seen in phthalocyanine compounds. Vibration peaks for phthalocyanine 5 were observed as aromatic $\mathrm{C}-\mathrm{H}$ at $3084 \mathrm{~cm}^{-1}, \mathrm{CH}_{2}$ at $2926 \mathrm{~cm}^{-1}, \mathrm{C}=\mathrm{C}$ at $1598 \mathrm{~cm}^{-1}$, and Ar-O-Ar at $1234 \mathrm{~cm}^{-1}$. Finally, the vibrations of phthalocyanine 6 were observed at aromatic $\mathrm{CH}$ peak $3018 \mathrm{~cm}^{-1}, \mathrm{CH}_{2}$ $2970 \mathrm{~cm}^{-1}, \mathrm{C}=\mathrm{C} 1598 \mathrm{~cm}^{-1}, \mathrm{Ar}-\mathrm{O}-$ Ar peak at $1238 \mathrm{~cm}^{-1}$ peaks appear to be in good harmony.

As expected in the ${ }^{1} \mathrm{H}$ NMR spectrum of compound 4 in DMSO- $\mathrm{d}_{6}$, aromatic protons were observed as multiplets in the 8.18-6.93 ppm range. $\mathrm{CH}_{2}$ protons located between oxygen and oxygen among the aliphatic protons were observed at $6.01 \mathrm{ppm}$, while the $\mathrm{CH}_{2}$ peak bound to single oxygen was observed at $5.14 \mathrm{ppm}$. The ${ }^{13} \mathrm{C}$ NMR spectrum of the compound in DMSO- $\mathrm{d}_{6}$ also gives the peaks of the expected aromatic and aliphatic carbon atoms of the compound. Here, the carbon peaks of nitrile were observed at 116.68-116.15 ppm, the aromatic carbon peaks at 162.09-106.50 ppm, the carbon peak of the $\mathrm{CH}_{2}$ atom between oxygen and oxygen at $101.59 \mathrm{ppm}$, and the carbon peak of single oxygen-bonded $\mathrm{CH}_{2}$ at 70.92 $\mathrm{ppm}$. These observed peaks are in good agreement with the structure of the compound. ${ }^{1} \mathrm{H}$ NMR and ${ }^{13} \mathrm{C}$ NMR spectra of this compound are given in Fig. 2-3. For zinc phthalocyanine compound $\mathbf{5},{ }^{1} \mathrm{H}$ NMR protons in DMSO- $\mathrm{d}_{6}$ are observed as multiplets between 7.24-6.07 ppm, while aliphatic $\mathrm{CH}_{2}$ protons are observed at $6.00 \mathrm{ppm}$ and $5.54 \mathrm{ppm}$. Due to its paramagnetic nature, ${ }^{1} \mathrm{H}$ NMR measurements of compound 6 were not made.

Mass spectra of compounds (4-6) confirmed the proposed structure with the molecular ion being identified at $393.08[\mathrm{M}+\mathrm{Na}]^{+}, 1545.31[\mathrm{M}+\mathrm{H}]^{+}$, and $1540.31[\mathrm{M}+\mathrm{H}]^{+}$, respectively. 
Another spectral device related to the structure of phthalocyanines is UV spectroscopy. It gives absorbance value for $\mathrm{Q}$ and $\mathrm{B}$ bands which are characteristic for phthalocyanines [17]. It also indicates that the phthalocyanine compound does not bind the metal bond [18]. For the phthalocyanines $\mathbf{5}$ and $\mathbf{6}$, the $\mathrm{Q}$ band absorption values in the THF solvent were measured as 676 and $668 \mathrm{~nm}$ respectively. The $\mathrm{B}$ band of compound 5 was found to be $348 \mathrm{~nm}$. These values are consistent with the tetra peripheral substitute structure. The absorption values of these compounds measured at different concentrations in THF are given in Fig. 4 and 5. As can be seen from these diagrams, these phthalocyanine compounds exist as monomers in the measured concentration range. This shows that it may be useful for some areas that wish to be non-aggregated (such as photodynamic therapy).

One of the foremost applications of phthalocyanine compounds is their use as a sensor agent in photodynamic therapy. For this application, the compound should exhibit fluorescence. The data obtained from fluorescence absorption, excitation, and emission spectra reveal fluorescence properties. Fluorescence absorption, excitation, and emission spectra of the zinc phthalocyanine compound observed is shown in Fig. 6. Stokes shifts are within the expected range for the phthalocyanine compound. The Stokes shift detected in tetrahydrofuran for this phthalocyanine is $10 \mathrm{~nm}$. The fluorescence emission was measured at $694 \mathrm{~nm}$, while the excitation value was 682 . The quantum yield of this compound $\left(\Phi_{\mathrm{F}}\right)$ was calculated as 0.30 . This value is higher than the unsubstituted zinc phthalocyanine value [19]. These spectral values are consistent with the studies given in the literature [20, 21]. These data strengthen the possibility that the compound can be used as a sensor.

In addition to the fluorescence properties and fluorescence quantum efficiencies of the photosensors considered for photodynamic therapy, they can show an effective photosensor effect with their ability to produce singlet oxygen. In this study, a chemical method was used for the singlet oxygen production test to determine the photosensory ability of the zinc phthalocyanine compound. The singlet oxygen quantum yield $\left(\Phi_{\Delta}\right)$ of phthalocyanines 5 was determined in DMSO by using 1,3-diphenylisobenzofuran (DPBF) as a singlet oxygen quencher. During the measurements, the $Q$ bands of phthalocyanine compound $\mathbf{5}$ did not change, while a decrease in DPBF absorbance was observed due to the reaction of singlet oxygen with DPBF (at $417 \mathrm{~nm})$. ( Fig.7). The $\Phi_{\Delta}$ value of compound $\mathbf{5}\left(\Phi_{\Delta}=0.57\right)$ was found to be lower than Std$\mathrm{ZnPc}$ [22]. Here, one of the factors that can affect singlet oxygen production is substituted (2- (benzo [d] $[1,3]$ dioxol-5-ylmethoxy) phenoxy) groups. The other is the electronic structure of the selected metal atom.

\section{Quantum chemical calculation instructions}

DFT calculations [23] [24] used in phthalocyanine compounds were carried out using the method coded 6-31G and LanL2DZ base set of this method in the Gaussian 09 program [25]. Within the scope of this study, optimization of metallo phthalocyanines in the gas phase and ground state was performed. Molecular orbital energies were calculated especially in phthalocyanine minimum energy optimization. The log and chk extension files obtained from the program were visualized with the program named Gauss View 6 and numerical data were transferred to tables. 


\section{Structure Details and Analysis}

The molecular structure optimized by the two methods of the zinc phthalocyanine compound is shown in Fig. 8, together with the bond length values. The optimized structural parameters calculated with the DFT/ B3LYP 6-31G - LanL2DZ basis set are determined. Here the planar structure of the nucleus of the phthalocyanine compound is obtained. The bond lengths and angles between the optimized molecular atoms were compared with each other using the two basis sets for MPc's, given in Table 1. When comparing the two methods, the bond lengths of the $\mathrm{M}-\mathrm{N}$ atoms in phthalocyanine nuclei were calculated as $2.00 \AA$ in Zn-N24 / B3LYP / 6-31G and $1.95 \AA$ in Co-N24 / B3LYP / LanL2DZ, respectively. In the second method, bond lengths were shorter. The small differences between them are due to the sensitivity of the methods and the metal atoms' radii. In the optimization, the phthalocyanine nucleus has a planar structure and the metal atom is positioned at an angle of about 90 . Dihedral angles of $\mathrm{Zn}-\mathrm{Pc}$ were calculated as N18-Zn41-N24-C23 179.5 , and N5-Zn41-N24-C20 -178.43 ${ }^{\circ}$ with 6-31G. Dihedral angles of Co-Pc were calculated as N5-Co169-N24-C20 0.98 and N18-Co169-N24-C23 $179.73^{\circ}$ with LanL2DZ basis sets. Both DFT methods with the basis sets demonstrate that the phthalocyanine compound is planar in accordance with the dihedral angles of about $180^{\circ}[26]$.

\section{HOMO and LUMO analysis}

Quantum chemical calculations are widely used to calculate basic electronic parameters related to orbitals in the molecule. As frontier orbital molecules, the Highest Occupied Molecular Orbital (HOMO) and the Lowest Unoccupied Molecular Orbital (LUMO) are important[27]. However, by using these values, the activity parameters and energy deficit of the molecule are calculated and the chemical character of the molecule is determined. Perturbation MO theory is based on the energy difference between HOMO and LUMO[28-30]. The closer the energy levels of the interacting MO's to each other, the stronger the interaction. That is, the smaller the HOMO - LUMO energy difference, the stronger the interaction of the reactants and the easier the reaction[31].

The calculated results and their comparison with the two methods are presented in Table 2. Fig. 9-10 is the density orbital representation of the HOMO and LUMO of the Zn-Pc and Co-Pc compounds in both methods. LUMO+1 and HOMO-1 graphs of the compound were also taken. Frontiers orbitals of Zn-Pc, HOMO -4.78 eV LUMO -2.60 eV value at DFT / B3LYP / 6-31G level of the molecule and for Co-Pc, HOMO $-4.96 \mathrm{eV}$ LUMO -2.77 eV values at DFT / B3LYP / LanL2DZ level were calculated. The HOMO and LUMO, frontiers orbitals also help determine the degree of activity and interaction of the molecule with other species [32-34]. HOMO, LUMO, and the chemical reactivity descriptors calculated in the two methods were correlated and shown in Fig. 11. This is due to the calculation accuracy of these two methods from different parameters.

\section{Nonlinear Optics (NLO) analysis}

The dipole moment, which is the specialty of energy, is applied intramolecular[35-37]. The dipole moment consists of Van der Waals-type intermolecular interactions and intermolecular attraction is strong. The 
electronic dipole moment and total dipole moment are listed in Table 3.

The dipole moment, molecular polarization and hyperpolarization values should be calculated to determine Nonlinear Optical (NLO) properties[29, 38-40]. In the Zn-Pc / 6-31G method / B3LYP basis set, the parameters are respectively $\mu=8.0 \mathrm{D}, \mathrm{a}=593.6 \mathrm{au}, \beta=5.03 \times 10^{-31} \mathrm{esu}$. Also, in the Co-Pc / LanL2DZ basic set, the parameters are respectively $\mu=8.4 \mathrm{D}, \mathrm{a}=593.5 \mathrm{au}, \beta=5.08 \times 10^{-31}$ esu. According to these values, the molecule has parametric quantities that can be considered as NLO materials.

\section{Molecular electrostatic potential (MEP)}

MEP maps provide information about the electronic charge distribution of a molecule. The density of the electron distribution on the molecule is useful for illuminating bonds with descriptors such as polarity, electronegativity. The electronic structure and molecular reactivity of complex molecules can exhibit rich topographic properties $[28,38,40-42]$.

In this study, electrophilic potential (MEP) maps of three phthalocyanine molecules were obtained. As shown in Fig. 7 they are visualized with MEP maps at the DFT / B3LYP method with 6-31G and LanL2DZ basis set using the GaussView 6.0 software. The MEP maps show that the region characterized by the blue color around the $\mathrm{Zn}$ and $\mathrm{Co}$ atoms have positive values. The red regions on the map indicate the region rich in electrons. The aromatic ring region shows an almost neutral potential, most of which is represented by a yellow-green color. Contour maps of phthalocyanines confirm negative and positive potential parameters in accordance with the electrostatic potential map (ESP). The phthalocyanine nucleus in the structures shows the delocalized structure and high stabilization with green-yellow colors in color. Moreover, in the MEP maps, the negative potentials are mainly found in, for example, 0-107 and 0-118, while the potential occurring around the $\mathrm{H}-147$ atom is the most positive. In terms of electronegativity, oxygen atoms can be interpreted higher than other atoms.

\section{Molecular docking analysis}

The protein crystal structure of different enzymes was selected for the phthalonitrile compound in the Protein Data Bank (http://www.rcsb.org). From these complexes, PDB codes were selected and retrieved from the Protein Data Bank. As protein receptors, human carbonic anhydrase isozyme II (PDB ID: 6R6F), acetylcholinesterase (PDB ID: 4RVK), and butyrylcholinesterase (PDB ID: 6SAM) enzymes were used. The Docking studies were performed using the commercial software Schrodinger suite version 10.2 Maestro. [43].

Ligand preparation and protein preparation via LigPrep, and Protein preparation modules were used in accordance with the previous studies[44-46]. In addition, enzyme inhibition in-silico study of phthalonitrile compound was conducted in this study. Enzyme binding affinity was found as -5.24 and $7.67 \mathrm{kcal}$ and gave well results. The best docking poses were selected for analysis of interactions, and protein-ligand interaction was presented with Discovery Studio Client 2017 software. 
Computational ADME modeling is a very mature but still-developing field. In silico ADME tools are routinely applied to drug design [47]. The synthesized phthalonitrile molecule also complied with the drug similarity rules and displayed acceptable predicted ADME properties. In the analysis made on

SwissADME: Drug similarity was evaluated a free web tool to evaluate. In this analysis, it was found to be compatible compared to the Lipinski (Pfizer) filter. The online servers SwissADME

(http://www.swissadme.ch/index.php) were employed to check the chemo-informatics and biological properties of this ligand molecule.

The results in Table 4 show that the compounds are compatible with MW $370.36 \mathrm{~g} / \mathrm{mol}(<500)$, LogP values according to the Lipinski rule[48] with $1.9(<5)$, and HBA $6(<10)$. Topological PSA $84.50<140 \mathrm{~A}^{2}$, and $A B S$ is $79.85 \%$.

With (6SAM BChE) phthalonitrile the compound AChE had the most effective coupling score (-7.69) and good binding affinity was obtained (Fig. 12). Here, when the ligand interactions with protein residues are evaluated, the strongest bindings were line up as TRP82 $3.09 \AA$ conventional hydrogen bond, TRP430 $3.05 \AA ̊$ conventional hydrogen bond, GLY116 $4.03 \AA$ Amide-pi Stacked. TRP82-4.30 Å residues and nitrile groups on the ligand were observed to frame the $\mathrm{H}$-bond side chain.

In docking of the compound with another enzyme (6R6F AC II), the glide score was calculated to be -6.219. TRP5 $2.11 \AA$ traditional hydrogen bond, HIS4 $2.42 \AA$ conventional hydrogen bond, GLN92 $2.59 \AA$ traditional hydrogen bond, HIS64 $4.83 \AA$ A pi-pi T-shaped, HIS94 $4.86 \AA$ pi-pi T-shaped, ALA65 $4.89 \AA$ คialkyl, LEU198 $4.91 \AA ̊$ pi-alkyl, VAL121 $4.54 \AA ̊$ formed pi-alkyl bonds.

Finally, in another docking with receptor $4 \mathrm{RVK}$ AChE, a docking score of -5.24 was obtained. This docking complex, respectively ASP148 exhibited interactions with $4.84 \AA$ pi-anion, GLU91 $4.47 \AA$ pi-anion, VAL23 $4.30 \AA ̊$ pi-alkyl, LEU137 5.26 ̊̊ and $5.37 \AA ̊$ pi-alkyl, LEU15 $4.05 \AA$ Å pi-alkyl, and TYR86 $3.08 \AA$ conventional hydrogen bonds (Fig. 13). Here, it was determined that the phthalonitrile compound on the three enzyme proteins exhibited good performance in enzyme inhibition. The ligand-receptor binding score in the docking study also correlated well with the published data[49, 50].

\section{Conclusion}

In this study 4-(2-(benzo[d] [1, 3] dioxol-5-ylmethoxy) phenoxy) phthalonitrile (4) and peripherally tetra substituted zinc(II) and cobalt(II) phthalocyanine derivatives (5-6) were synthesized. The compounds (4-6) were characterized spectroscopically. In addition to the non-aggregating properties of the studied compounds, the fluorescence emission property of the zinc phthalocyanine compound and the singlet oxygen production capability show the potential to be used as a photosensor. The quantum chemical calculations are that both MPcs have very similar structures in the gas phase. We used the DFT / B3LYP method, which uses the 6-31 G and LanL2DZ basis set to determine and analyze geometric optimization. Frontier orbitals, HOMO-LUMO bandgap, and global parameters are close to each other when comparing phthalocyanine with the different central atoms via the different basis sets. The dipole moments of the 
$\mathrm{Zn}-\mathrm{Pc}$ and Co-Pc, the investigated compounds, are close to each other, respectively, 8.00 and 8.38 Debye. This value is promising for the use of non-linear materials. The synthesized phthalonitrile molecule was also made docking study for compliance with drug similarity rules and it was observed that it exhibits acceptable predicted ADME properties.

\section{Declarations}

\section{Author Declarations}

No living material requiring ethical approval was used in the study. The article prepared for publication has the consent of all authors. Data are included in the article. There are no other persons who satisfied the criteria for authorship but are not listed.

\section{Author contribution statement}

MSA conceived the study; DGS conducted the experiments; ÜY conducted the DFT and docking. MSA and ÜY wrote the manuscript, and all authors read, edited, and approved the manuscript.

\section{Funding sources}

This research did not receive any specific grant from funding agencies in the public, commercial or notfor-profit sectors.

\section{Conflict of interest}

The authors declare no conflict of interest.

\section{Data availability statement}

The datasets generated during and/or analyzed during the current study are available from the corresponding author on reasonable re-quest

\section{References}

1. Haroun AA, Diab HA, Hakeim OA (2016) Cellulosic fabrics printing with multifunctional encapsulated phthalocyanine pigment blue using phase separation method. Carbohydr Polym 146:102-108

2. Anghelone $M$, Jembrih-Simbürger $D$, Schreiner $M$ (2015) Identification of copper phthalocyanine blue polymorphs in unaged and aged paint systems by means of micro-Raman spectroscopy and Random Forest. SPECTROCHIM ACTA A 149:419-425

3. Ghasemi M, Daud WRW, Rahimnejad M, Rezayi M, Fatemi A, Jafari Y, Somalu MR, Manzour A (2013) Copper-phthalocyanine and nickel nanoparticles as novel cathode catalysts in microbial fuel cells. Int J Hydrog Energy 38:9533-9540 
4. Diab N, Morales DM, Andronescu C, Masoud M, Schuhmann W (2019) A sensitive and selective graphene/cobalt tetrasulfonated phthalocyanine sensor for detection of dopamine. Sens Actuators B Chem 285:17-23

5. Chaabene M, Gassoumi B, Mignon P, Ben Chaâbane R, Allouche A-R (2019) New zinc phthalocyanine derivatives for nitrogen dioxide sensors: A theoretical optoelectronic investigation. J Mol Graph 88:174-182

6. Kong S, Wang X, Bai L, Song Y, Meng F (2019) Multi-arm ionic liquid crystals formed by pyridinemesophase and copper phthalocyanine. J Mol Liq 288:111012

7. Matshitse R, Khene S, Nyokong T (2019) Photophysical and nonlinear optical characteristics of pyridyl substituted phthalocyanine - Detonation nanodiamond conjugated systems in solution. Diam Relat Mater 94:218-232

8. Fashina A, Nyokong T (2015) Nonlinear optical response of tetra and mono substituted zinc phthalocyanine complexes. J Lumin 167:71-79

9. Güngördü Solğun D, Horoz S, Ağırtaş MS (2018) Synthesis of novel tetra (4-tritylphenoxy) substituted metallophthalocyanines and investigation of their aggregation, photovoltaic, solar cell properties. Inorg Nano-Met Chem 48:508-514

10. McRae EKS, Nevonen DE, McKenna SA, Nemykin VN (2019) Binding and photodynamic action of the cationic zinc phthalocyanines with different types of DNA toward understanding of their cancer therapy activity. J Inorg Biochem 199:110793

11. Doustvandi MA, Mohammadnejad F, Mansoori B, Tajalli H, Mohammadi A, Mokhtarzadeh A, Baghbani E, Khaze V, Hajiasgharzadeh K, Moghaddam MM, Hamblin MR, Baradaran B (2019) Photodynamic therapy using zinc phthalocyanine with low dose of diode laser combined with doxorubicin is a synergistic combination therapy for human SK-MEL-3 melanoma cells. Photodiagn Photodyn Ther 28:88-97

12. Ağirtaş MS, Cabir B, Gümüş S, Özdemir S, Dündar A (2018) Synthesis and antioxidant, aggregation, and electronic properties of 6-tert-butyl-1,4-benzodioxine substituted phthalocyanines. Turk J Chem 42:100-111

13. Salih Ağırtaş M (2008) Highly soluble phthalocyanines with hexadeca tert-butyl substituents. Dyes Pigm 79:247-251

14. Ağırtaş MS, Cabir B, Özdemir S, Okumus V, Arslantas A (2017) Synthesis, Aggregation, Antioxidant and DNA-Binding Properties of Metallophthalocyanines Bearing 5-Tert-butyl-2-hydroxyphenoxy Groups. 2: 11352-11357

15. Urbani M, Ragoussi M-E, Nazeeruddin MK, Torres T (2019) Phthalocyanines for dye-sensitized solar cells. Coord Chem Rev 381:1-64

16. Attia MS, Ali K, El-Kemary M, Darwish WM (2019) Phthalocyanine-doped polystyrene fluorescent nanocomposite as a highly selective biosensor for quantitative determination of cancer antigen 125 . Talanta 201:185-193 
17. Wierzchowski M, Sobotta L, Łażewski D, Kasprzycki P, Fita P, Goslinski T (2020) Spectroscopic and quantum chemical study of phthalocyanines with 1,4,7-trioxanonyl moieties. J Mol Struct 1203:127371

18. Ziminov AV, Sidunets YA, Fundamensky VS, Gurzhiy VV, Ramsh SM (2020) Synthesis, characterization, and investigation of photochemical properties of tetra-substituted zinc phthalocyanines bearing 4-(3,5-dimethyl-1 H-pyrazol-1-yl)phenyl moiety with different linker heteroatoms. Inorg Chim Acta 501:119306

19. Demirbaş Ü, Bayrak R, Dilber G, Menteşe E, Akçay HT (2019) Novel triazole substituted phthalocyanines showing high singlet oxygen quantum yields. J Lumin 206:199-204

20. Durmuş $M$, Nyokong $T$ (2008) Photophysicochemical and fluorescence quenching studies of benzyloxyphenoxy-substituted zinc phthalocyanines. SPECTROCHIM ACTA A 69:1170-1177

21. Ogunsipe A, Maree D, Nyokong $T$ (2003) Solvent effects on the photochemical and fluorescence properties of zinc phthalocyanine derivatives. J Mol Struct 650:131-140

22. Şahal H, Pişkin M, Organ GA, Öztürk Ö F, Kaya M, Canpolat E (2018) Zinc(II) phthalocyanine containing Schiff base containing sulfonamide: synthesis, characterization, photophysical, and photochemical properties. J Coord Chem 71:3763-3775

23. Frisch MJTG, Schlegel HB, Scuseria GE, Robb MA, Cheeseman JR, Montgomery JA Jr, Vreven T, Kudin KN, Burant JC, Millam JM, lyengar SS, Tomasi J, Barone V, Mennucci B, Cossi M, Scalmani G, Rega N, Petersson GA, Nakatsuji H, Hada M, Ehara M, Toyota K, Fukuda R, Hasegawa J, Ishida M, Nakajima T, Honda Y, Kitao O, Nakai H, Klene M, Li X, Knox JE, Hratchian HP, Cross JB, Bakken V, Adamo C, Jaramillo J, Gomperts R, Stratmann RE, Yazyev O, Austin AJ, Cammi R, Pomelli C, Ochterski JW, Ayala PY, Morokuma K, Voth GA, Salvador P, Dannenberg JJ, Zakrzewski VG, Dapprich S, Daniels AD, Strain MC, Farkas O, Malick DK, Rabuck AD, Raghavachari K, Foresman JB, Ortiz JV, Cui Q, Baboul AG, Clifford S, Cioslowski J, Stefanov BB, Liu G, Liashenko A, Piskorz P, Komaromi I, Martin RL, Fox DJ, Keith T, Al-Laham MA, Peng CY, Nanayakkara A, Challacombe M, Gill PMW, Johnson B, Chen W, Wong MW, Gonzalez C, Pople JA (2016) Gaussian 09, Revision A.02, Gaussian, Inc., Wallingford CT,

24. Ramos JM, Versiane O, Felcman J, Téllez SC, A (2009) FT-IR vibrational spectrum and DFT:B3LYP/6$31 \mathrm{G}$ and B3LYP/6-311G structure and vibrational analysis of glycinate-guanidoacetate nickel (II) complex: [Ni(Gly)(Gaa)]. SPECTROCHIM ACTA A 72:182-189

25. Lee C, Yang W, Parr RG (1988) Development of the Colle-Salvetti correlation-energy formula into a functional of the electron density. Phys Rev B 37:785-789

26. Basova T, Hassan A, Durmul M, Gürek AG, Ahsen V (2016) Liquid crystalline metal phthalocyanines: Structural organization on the substrate surface. Coord Chem Rev 310:131-153

27. Pereira F, Xiao K, Latino DARS, Wu C, Zhang Q, Aires-de-Sousa J (2017) Machine Learning Methods to Predict Density Functional Theory B3LYP Energies of HOMO and LUMO Orbitals. J Chem Inf Model 57:11-21 
28. Arivazhagan M, Senthil kumar J (2015) Molecular structure, vibrational spectral assignments, HOMO-LUMO, MESP, Mulliken analysis and thermodynamic properties of 2,6-xylenol and 2,5dimethyl cyclohexanol based on DFT calculation. SPECTROCHIM ACTA A. 137: 490-502

29. Khajehzadeh M, Moghadam M (2017) Molecular structure, FT IR, NMR, UV, NBO and HOMO-LUMO of 1-(3-(dimethylamino)propyl)-1-(4-fluorophenyl)-1,3-dihydroisobenzofuran-5-carbonitrile by DFT/B3LYP and PBEPBE methods with LanL2DZ and 6-311 + $+\mathrm{G}(\mathrm{d}, 2 \mathrm{p})$ basis sets. SPECTROCHIM ACTA A 180:51-66

30. Prabhaharan M, Prabakaran AR, Gunasekaran S, Srinivasan S (2015) DFT studies on vibrational spectra, HOMO-LUMO, NBO and thermodynamic function analysis of cyanuric fluoride. SPECTROCHIM ACTA A 136:494-503

31. Kaur I, Jia W, Kopreski RP, Selvarasah S, Dokmeci MR, Pramanik C, McGruer NE, Miller GP (2008) Substituent Effects in Pentacenes: Gaining Control over HOMO - LUMO Gaps and Photooxidative Resistances. J Am Chem Soc 130:16274-16286

32. Govindarajan M, Karabacak M (2012) Spectroscopic properties, NLO, HOMO-LUMO and NBO analysis of 2,5-Lutidine. SPECTROCHIM ACTA A 96:421-435

33. Kim B-G, Ma X, Chen C, le Y, Coir EW, Hashemi H, Aso Y, Green PF, Kieffer J, Kim J (2013) Energy Level Modulation of HOMO, LUMO, and Band-Gap in Conjugated Polymers for Organic Photovoltaic Applications. 23: 439-445

34. Latha B, Kumaresan P, Nithiyanantham S, Sampathkumar K (2018) HOMO-LUMO analysis of multi walled carbon nanotubes doped Tetrafluoro Phthalate crystals for nonlinear optical applications. $J$ Mol Struct 1152:351-360

35. Demircioğlu Z, Kaştaş G, Kaştaş ÇA, Frank R (2019) Spectroscopic, XRD, Hirshfeld surface and DFT approach (chemical activity, ECT, NBO, FFA, NLO, MEP, NPA\& MPA) of (E)-4-bromo-2-[(4bromophenylimino)methyl]-6-ethoxyphenol. J Mol Struct 1191:129-137

36. Guidara S, Feki H, Abid Y (2015) Structural, vibrational, NLO, MEP, NBO analysis and DFT calculation of bis 2,5-dimethylanilinium sulfate. J Mol Struct 1080:176-187

37. Sayin K, Karakaş D (2015) Structural, spectral, NLO and MEP analysis of the [MgO2Ti2(OPri)6], [MgO2Ti2(OPri)2(acac)4] and [MgO2Ti2(OPri)2(bzac)4] by DFT method. SPECTROCHIM ACTA A 144:176-182

38. Binoy J, Marchewka MK, Jayakumar VS (2013) The 'partial resonance' of the ring in the NLO crystal melaminium formate: Study using vibrational spectra, DFT, HOMO-LUMO and MESP mapping. SPECTROCHIM ACTA A 104:97-109

39. Srivastava AK, Pandey AK, Jain S, Misra N (2015) FT-IR spectroscopy, intra-molecular C - H … interactions, HOMO, LUMO, MESP analysis and biological activity of two natural products, triclisine and rufescine: DFT and QTAIM approaches. Spectrochim Acta A Mol Biomol Spectrosc 136:682-689

40. Alam M, Park S (2018) Molecular structure, spectral studies, NBO, HOMO-LUMO profile, MEP and Mulliken analysis of 3 $\beta, 6 \beta$-dichloro-5a-hydroxy-5a-cholestane. J Mol Struct 1159:33-45 
41. Eşme A, Sağdınç SG (2017) Spectroscopic (FT-IR, FT-Raman, UV-Vis) analysis, conformational, HOMO-LUMO, NBO and NLO calculations on monomeric and dimeric structures of 4pyridazinecarboxylic acid by HF and DFT methods. J Mol Struct 1147:322-334

42. Costa RA, Pitt PO, Pinheiro MLB, Oliveira KMT, Salomé KS, Barison A, Costa EV (2017) Spectroscopic investigation, vibrational assignments, HOMO-LUMO, NBO, MEP analysis and molecular docking studies of oxoaporphine alkaloid liriodenine. SPECTROCHIM ACTA A 174:94-104

43. Biovia D, Berman H, Westbrook J, Feng Z, Gilliland G, Bhat T, Richmond T J T J o C P, (2000) Dassault Systèmes BIOVIA, Discovery Studio Visualizer, v. 17.2, San Diego: Dassault Systèmes, 2016. 10: 0021-9991

44. Channa Basappa V, Hamse Kameshwar V, Kumara K, Achutha DK, Neratur Krishnappagowda L, Kariyappa AK (2020) Design and synthesis of coumarin-triazole hybrids: biocompatible anti-diabetic agents, in silico molecular docking and ADME screening. Heliyon 6:e05290

45. Adiguzel R, Türkan F, Yildiko Ü, Aras A, Evren E, Onkol T (2021) Synthesis and in silico studies of Novel Ru(II) complexes of Schiff base derivatives of 3-[(4-amino-5-thioxo-1,2,4-triazole-3yl)methyl]-2(3H)-benzoxazolone compounds as potent Glutathione S-transferase and Cholinesterases Inhibitor. J Mol Struct 1231:129943

46. Aras A, Türkan F, Yildiko U, Atalar MN, Kılıç Ö, Alma MH, Bursal E (2021) Biochemical constituent, enzyme inhibitory activity, and molecular docking analysis of an endemic plant species, Thymus migricus. Chem Pap 75:1133-1146

47. Corvaro M, Bartels M (2019) The ADME profile of the fungicide tricyclazole in rodent via the oral route: A critical review for human health safety assessment. Regul Toxicol Pharmacol 108:104438

48. Athar Abbasi M, Raza H, Aziz ur R, Zahra Siddiqui S, Adnan Ali Shah S, Hassan M, Seo S-Y (2019) Synthesis of novel N-(1,3-thiazol-2-yl)benzamide clubbed oxadiazole scaffolds: Urease inhibition, Lipinski rule and molecular docking analyses. Bioorg Chem 83:63-75

49. Larik FA, Saeed A, Faisal M, Hamdani S, Jabeen F, Channar PA, Mumtaz A, Khan I, Kazi MA, Abbas Q, Hassan M, Korabecny J, Seo S-Y (2020) Synthesis, inhibition studies against AChE and BChE, druglike profiling, kinetic analysis and molecular docking studies of N-(4-phenyl-3-aroyl-2(3H)-ylidene) substituted acetamides. J Mol Struct 1203:127459

50. Wang S, Wu C, Liu Z, You H (2018) Studies on the interaction of BDE-47 and BDE-209 with acetylcholinesterase (AChE) based on the neurotoxicity through fluorescence, UV-vis spectra, and molecular docking. Toxicol Lett 287:42-48

\section{Tables}

Table 1 Theoretically obtained bond lengths $(\AA)$ and bond angles $\left(^{\circ}\right)$ of the molecules with the DFT optimizations. 


\begin{tabular}{llrrrlrr}
\hline Atom Groups & \multicolumn{2}{c}{ Bond Lengths } & \multicolumn{2}{l}{ Atom Groups } & \multicolumn{2}{c}{ Bond Angles } \\
\hline & & Zn-6-31G & Co-LanL2DZ & & Zn-6-31G & Co-LanL2DZ \\
\hline 1 & C29-C30 & 1.39 & 1.40 & 14 & C29-C30-C31 & 120.23 & 120.22 \\
2 & C68-C69 & 1.40 & 1.42 & 15 & C68-C69-C70 & 121.71 & 120.55 \\
\hline 3 & C54-C55 & 1.41 & 1.39 & 16 & C33-C21-C22 & 120.56 & 120.34 \\
\hline 4 & O77-C75 & 1.40 & 1.41 & 17 & C127-0132-C133 & 105.73 & 106.51 \\
\hline 5 & 064-C65 & 1.46 & 1.46 & 18 & C146-0145-C136 & 118.60 & 120.03 \\
\hline 6 & O131-C132 & 1.47 & 1.48 & 19 & C1-N5-C4 & 108.95 & 107.07 \\
\hline 7 & N6-C23 & 1.33 & 1.33 & 20 & C8-N12-C11 & 109.15 & 107.25 \\
\hline 8 & N13-C14 & 1.33 & 1.33 & 21 & C23-N20-C20 & 109.12 & 108.42 \\
\hline 9 & N5-C1 & 1.38 & 1.33 & 22 & C69-C71-H76 & 121.72 & 120.38 \\
\hline 10 & C69-H72 & 1.08 & 1.08 & 23 & C29-C30-H45 & 120.37 & 118.75 \\
\hline 11 & C57-H61 & 1.08 & 1.08 & 24 & N12-(Zn, Co)-N5 & 89.72 & 89.83 \\
\hline 12 & C114-H117 & 1.08 & 1.08 & 25 & N18-(Zn, Co)-N12 & 90.20 & 90.16 \\
\hline 13 & (Zn, Co)-N24 & 2.00 & 1.95 & 26 & N24-(Zn, Co)-N18 & 89.88 & 89.91 \\
\hline
\end{tabular}

Table 2 Comparison of HOMO, LUMO, and the reactivities by Zn-Pc, 6-31G, and Co-Pc, LanL2DZ basis sets in the ground state.

\begin{tabular}{lrr}
\hline Molecules Energy & Zn, 6-31G $(\mathrm{eV})$ & Co, LanL2DZ $(\mathrm{eV})$ \\
\hline ELUMO & -2.60 & -2.76 \\
EHOMO & -4.78 & -4.96 \\
\hline ELUMO+1 & -2.59 & -2.76 \\
\hline EHOMO-1 & -5.75 & -5.92 \\
\hline Energy Gap $(\Delta)|\mathrm{EHOMO}-\mathrm{ELUMO}|$ & 2.18 & 2.19 \\
\hline Ionization Potential $(\mathrm{I}=-\mathrm{EHOMO})$ & 4.78 & 4.96 \\
\hline Electron Affinity $(\mathrm{A}=-\mathrm{ELUMO})$ & 2.60 & 2.7715 \\
\hline Chemical hardness $(\eta=(\mathrm{I}-\mathrm{A}) / 2)$ & 1.09 & 1.10 \\
\hline Chemical softness $(\mathrm{s}=1 / 2 \eta)$ & 0.55 & 0.55 \\
\hline Chemical Potential $(\mu=-(\mathrm{I}+\mathrm{A}) / 2)$ & -3.48 & -3.58 \\
\hline Electronegativity $(\chi=(1+\mathrm{A}) / 2)$ & 1.80 & 1.9 \\
\hline Electrophilicity $i n d e x(\omega=\mu 2 / 2 \eta)$ & 5.56 & 5.84 \\
\hline
\end{tabular}

Table 3 The dipole moments (Debye), (au) polarizability, $\beta$ components, and $\beta$ tot of ZnPc,6-31G, and Co-Pc, LanL2DZ. 


\begin{tabular}{lrrlrr}
\hline Parameters & Zn-Pc & Co-Pc & Parameters & Zn-Pc & Co-Pc \\
\hline$\mu_{(\mathrm{X})}$ & -1.5 & -1.2 & $\beta_{(\mathrm{XXX})}$ & -153.9 & -188.3 \\
$\mu_{(\mathrm{Y})}$ & 2.7 & 2.8 & $\beta_{(\mathrm{XXY})}$ & -191.9 & -201.1 \\
\hline$\mu_{(\mathrm{Z})}$ & 7.4 & 7.8 & $\beta_{(\mathrm{XYY})}$ & 156.4 & 213.0 \\
\hline$\mu_{(\mathrm{D})}$ & 8.0 & 8.4 & $\beta_{(\mathrm{YYY})}$ & 540.1 & 579.6 \\
\hline$\alpha_{(\mathrm{XX})}$ & -537.9 & -528.5 & $\beta_{(\mathrm{XXZ})}$ & 148.8 & 174.8 \\
\hline$\alpha_{(\mathrm{YY})}$ & -621.9 & -622.1 & $\beta_{(\mathrm{XYZ})}$ & -61.0 & -60.6 \\
\hline$\alpha_{(\mathrm{ZZ})}$ & -621.1 & -630.0 & $\beta_{(\mathrm{YYZ})}$ & 129.4 & 142.89 \\
\hline$\alpha_{(\mathrm{XY})}$ & -8.6 & -10.1 & $\beta_{(\mathrm{XZZ})}$ & 62.9 & 77.6 \\
\hline$\alpha_{(\mathrm{XZ})}$ & 8.8 & 10.4 & $\beta_{(\mathrm{YZZ})}$ & -12.3 & -8.5 \\
\hline$\alpha_{(\mathrm{YZ})}$ & 5.6 & 6.1 & $\beta_{(\mathrm{ZZZ})}$ & 91.1 & 118.3 \\
\hline$\alpha_{(\mathrm{au})}$ & 593.6 & 593.5 & $\beta_{(\mathrm{esu})}$ & $5.03 \times 10^{-31}$ & $5,08 \times 10^{-31}$ \\
\hline
\end{tabular}

Table 4 Physicochemical and lipophilicity of the compound using SwissADME software

\begin{tabular}{|c|c|c|c|c|c|c|c|c|c|c|}
\hline \multirow[t]{2}{*}{ Code } & \multirow{2}{*}{$\begin{array}{l}\text { Lipophilicity } \\
\text { consensus log P }\end{array}$} & \multicolumn{9}{|c|}{ Physicochemical properties } \\
\hline & & $\begin{array}{l}\mathrm{MW}^{\mathrm{a}} \\
\mathrm{g} / \mathrm{mol}\end{array}$ & $\begin{array}{l}\text { Heavy } \\
\text { atoms }\end{array}$ & $\begin{array}{l}\text { Aromatic } \\
\text { heavy atoms }\end{array}$ & $\begin{array}{l}\text { Rot. } \\
\text { bond }\end{array}$ & $\begin{array}{l}\text { H-bond } \\
\text { acc. }\end{array}$ & $\begin{array}{l}\text { H-bond } \\
\text { don. }\end{array}$ & $\mathrm{MR}^{\mathrm{b}}$ & $\begin{array}{l}\text { TPSA }^{\mathrm{c}} \\
\left(\mathrm{A}^{2}\right)\end{array}$ & $\begin{array}{l}\% \\
\mathrm{ABS}^{\mathrm{d}}\end{array}$ \\
\hline 4 & 1.90 & 370.36 & 28 & 18 & 5 & 6 & - & 99.43 & 84.50 & 79.85 \\
\hline
\end{tabular}

${ }^{\mathrm{a}} \mathbf{M W}$, molecular weight; ${ }^{\mathrm{b}} \mathbf{M R}$, molar refractivity; ${ }^{\mathrm{C}}$ TPSA, topological polar surface area; d\%ABS: percentage of absorption $(\% A B S=109-[0.345 \times$ TPSA $]$.

Figures 


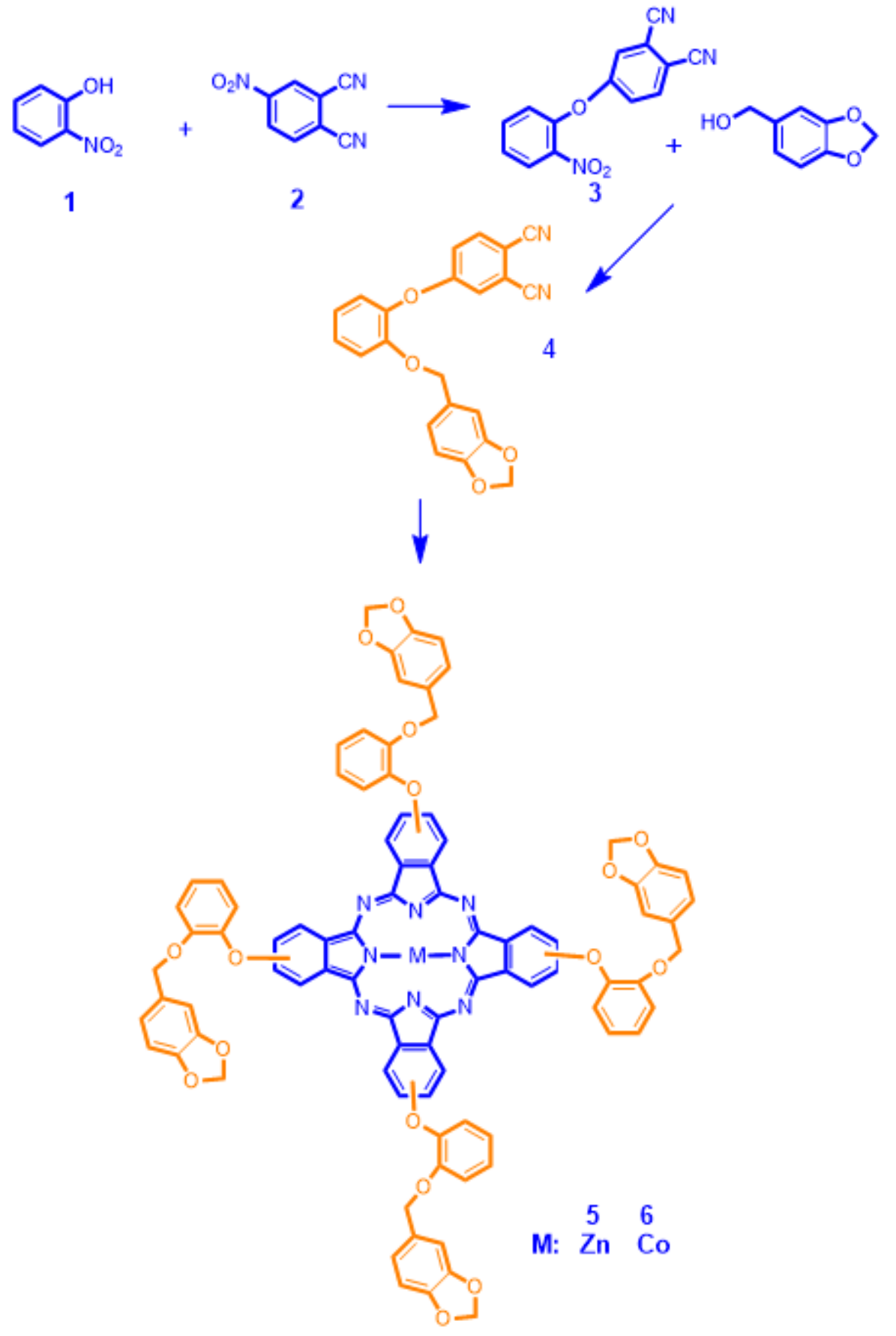

Figure 1

Synthesis of compounds 4-6. 


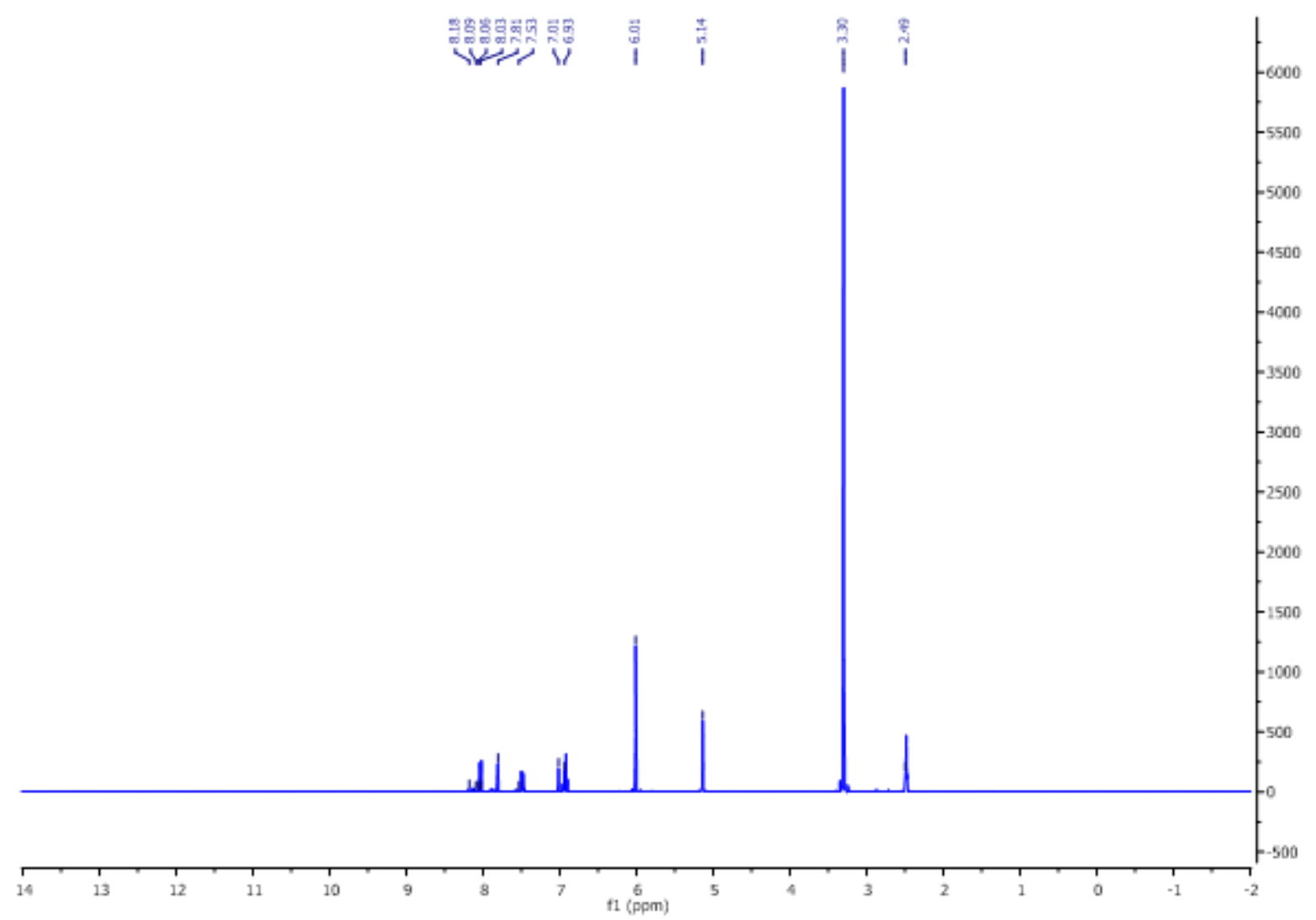

Figure 2

1H NMR spectrum of compound 4. 


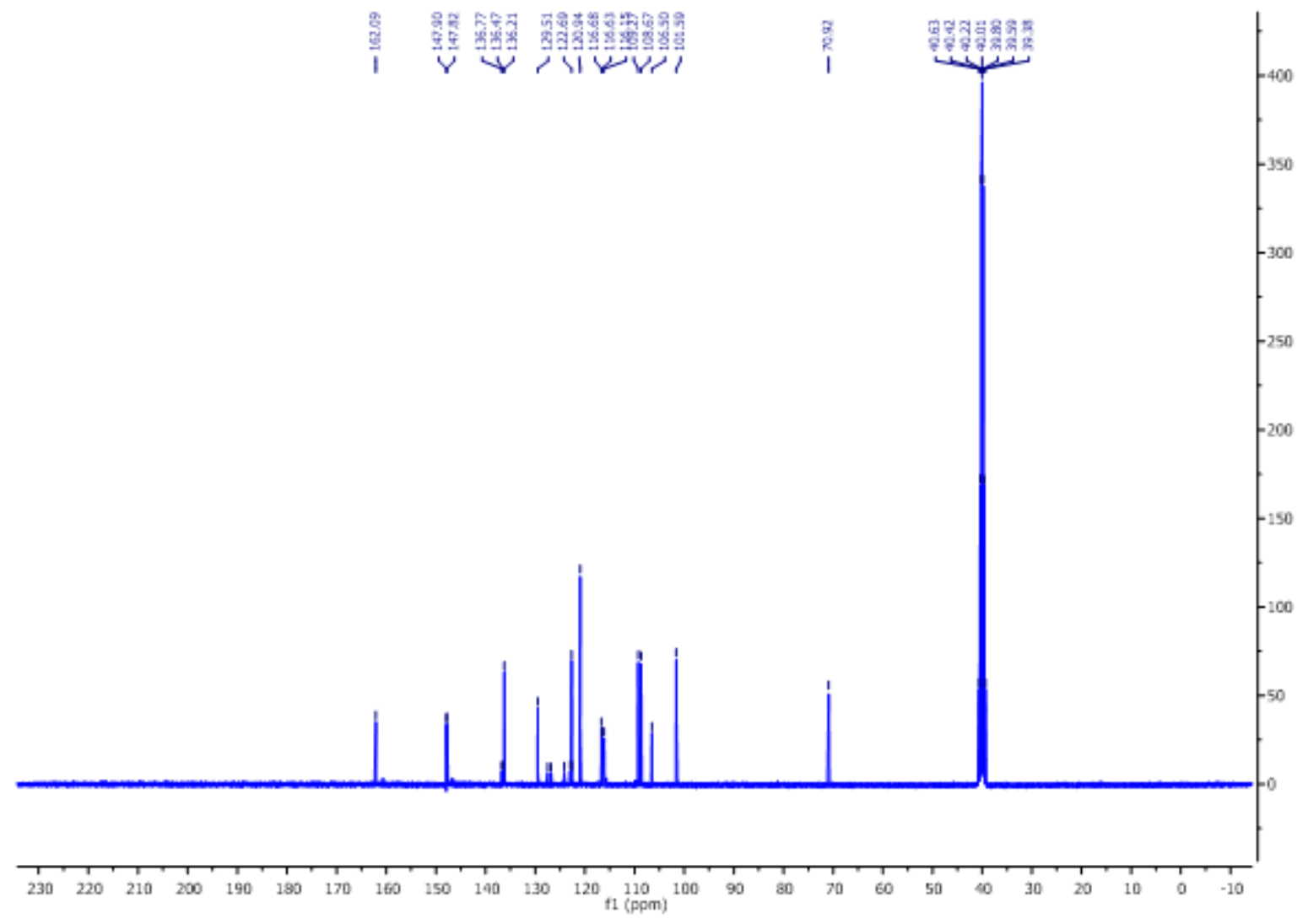

Figure 3

13C NMR spectrum of compound 4. 


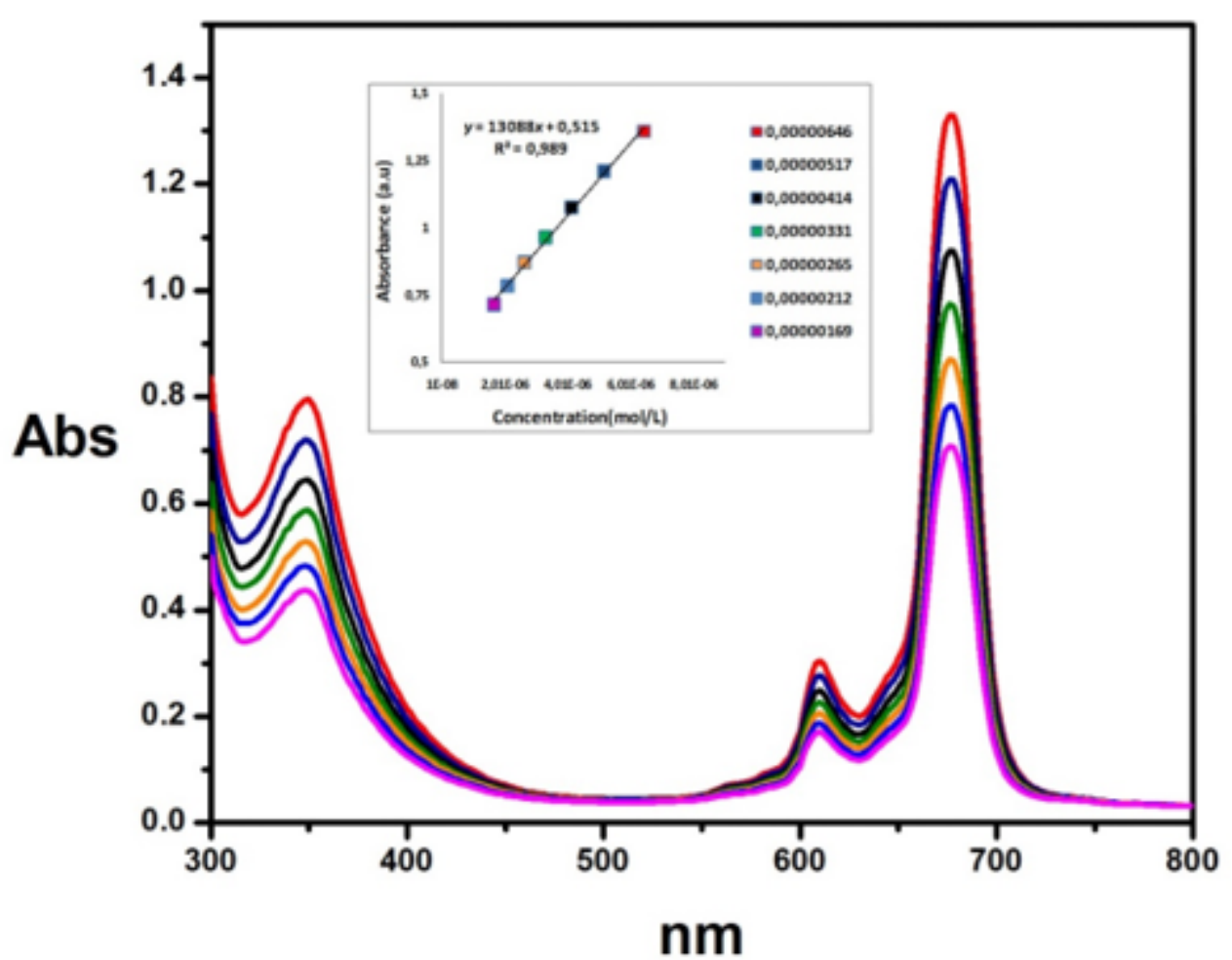

Figure 4

Aggregation of compound 5 .

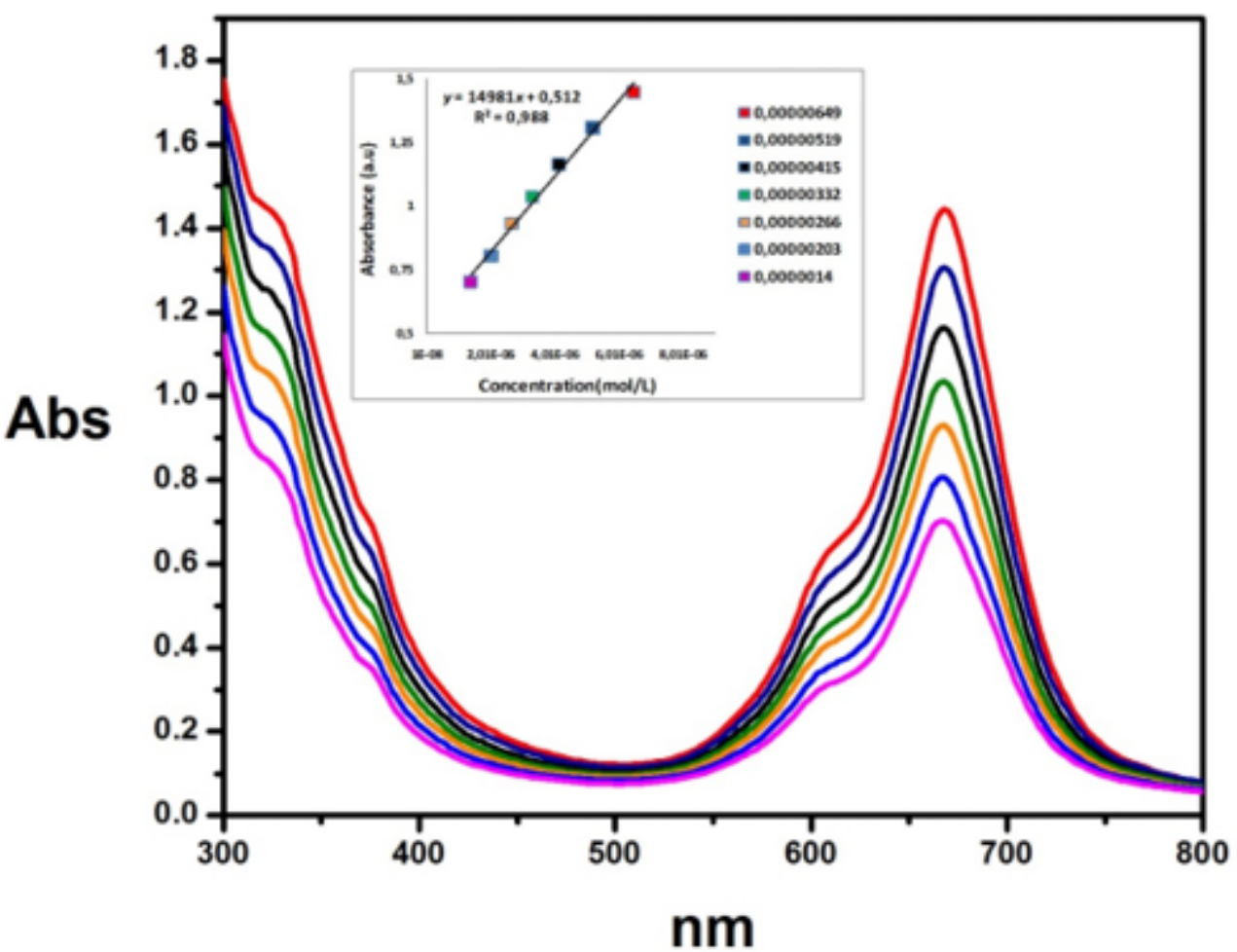


Figure 5

Aggregation of compound 6 .

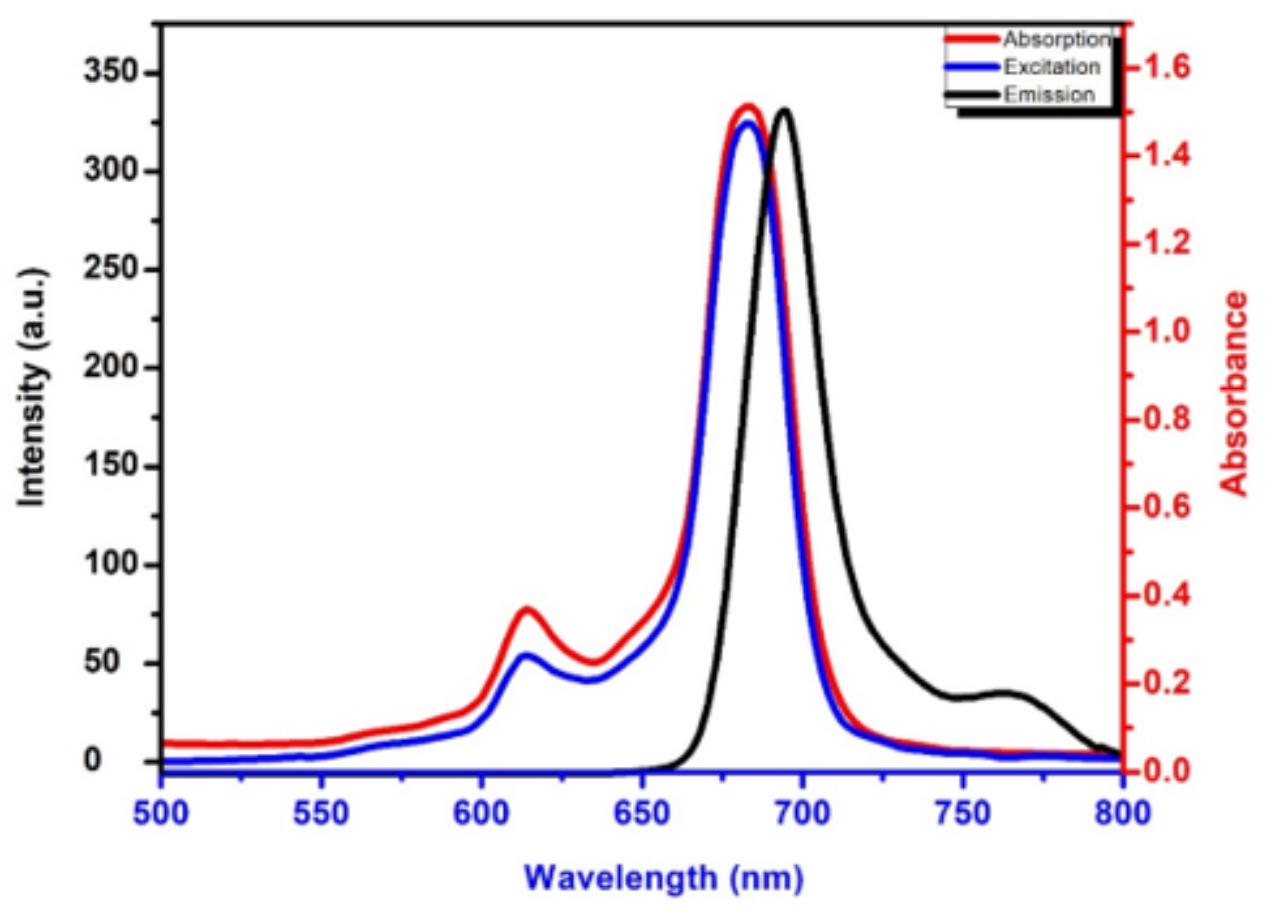

Figure 6

Emission, excitation, and absorption zinc phthalocyanine 5 in DMSO.

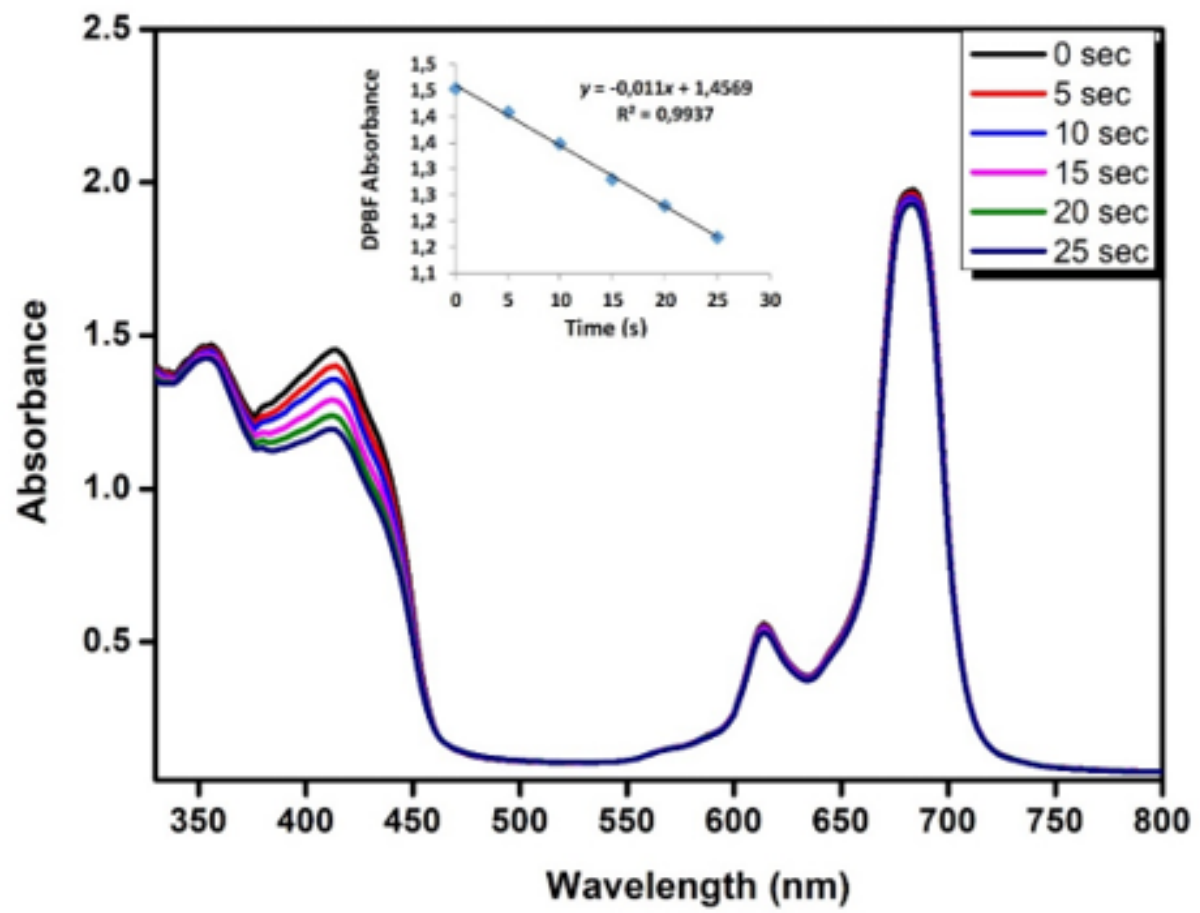

Figure 7 
The typical electronic spectrum for the determination of singlet oxygen quantum yield for phthalocyanine 5 in DMSO at a concentration of 1×10-5 M (Inset: Plots of DPBF absorbance versus time).

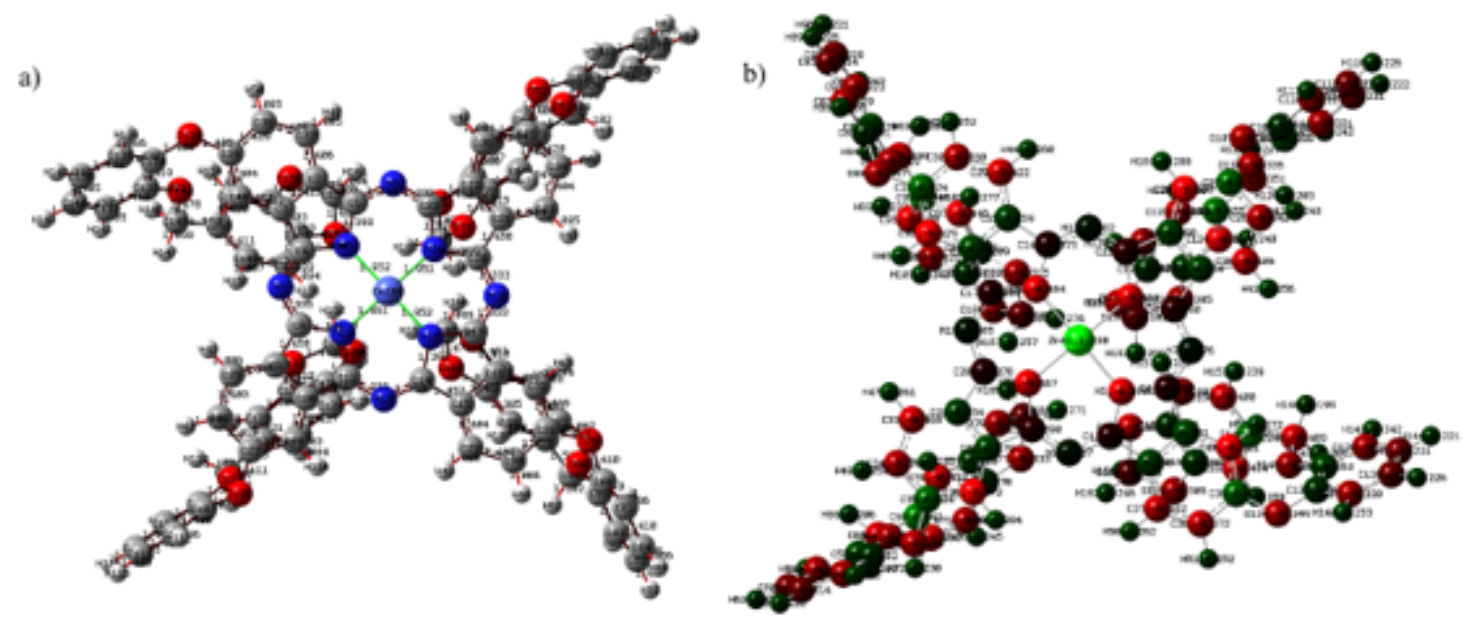

Figure 8

M-Pcs optimized molecular structure by DFT / B3LYP methods with 6-31G, Zn-Pc (a) and Co-Pc (b), LanL2DZ basis sets. 

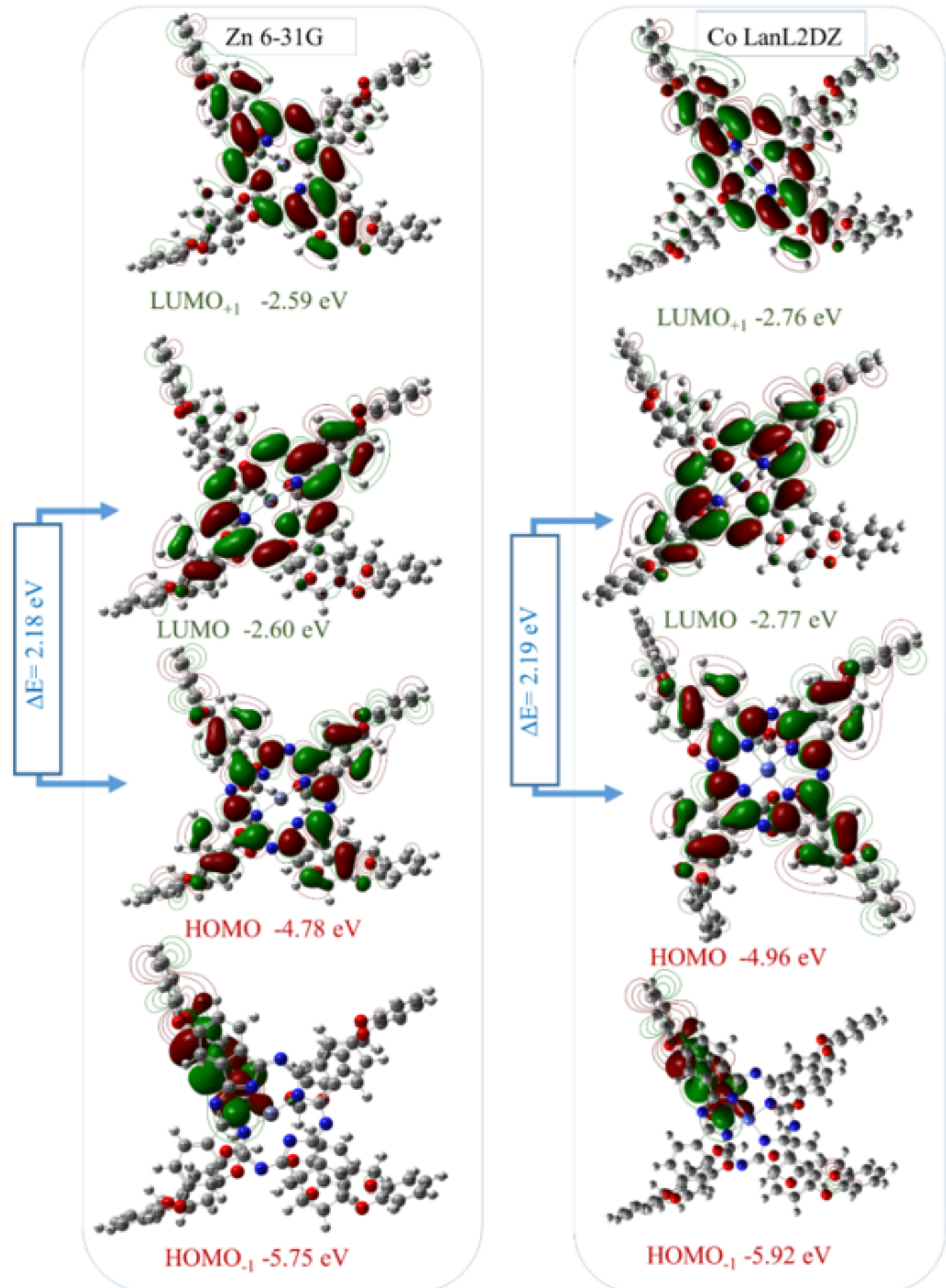

Figure 9

Frontier molecular orbitals of zinc phthalocyanine compound by B3LYP/6-31G and cobalt phthalocyanine compound by B3LYP/LanL2DZ basis set. 
a)

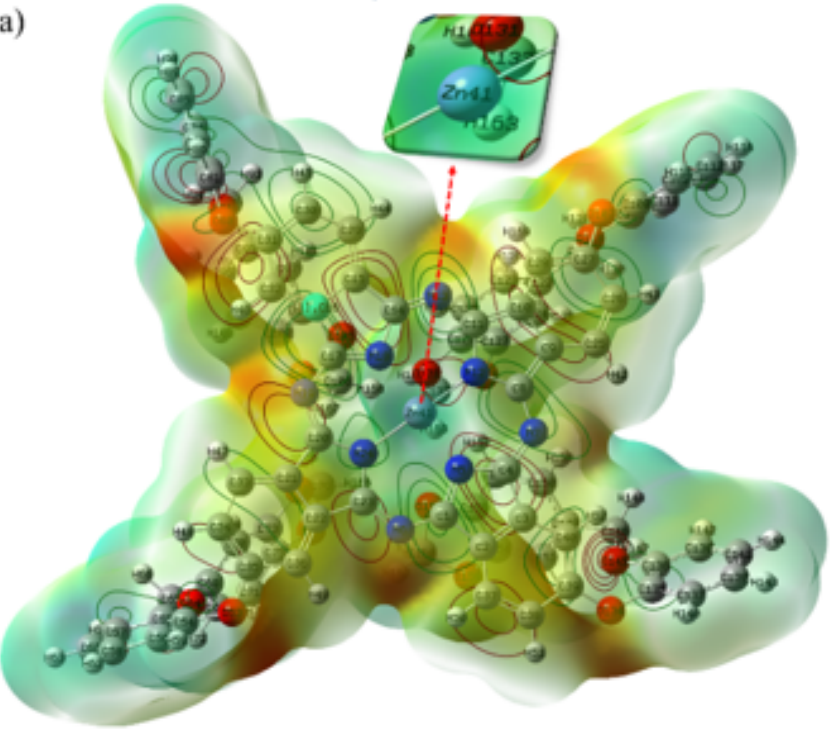

$-5.42 \mathrm{e}^{-2}$

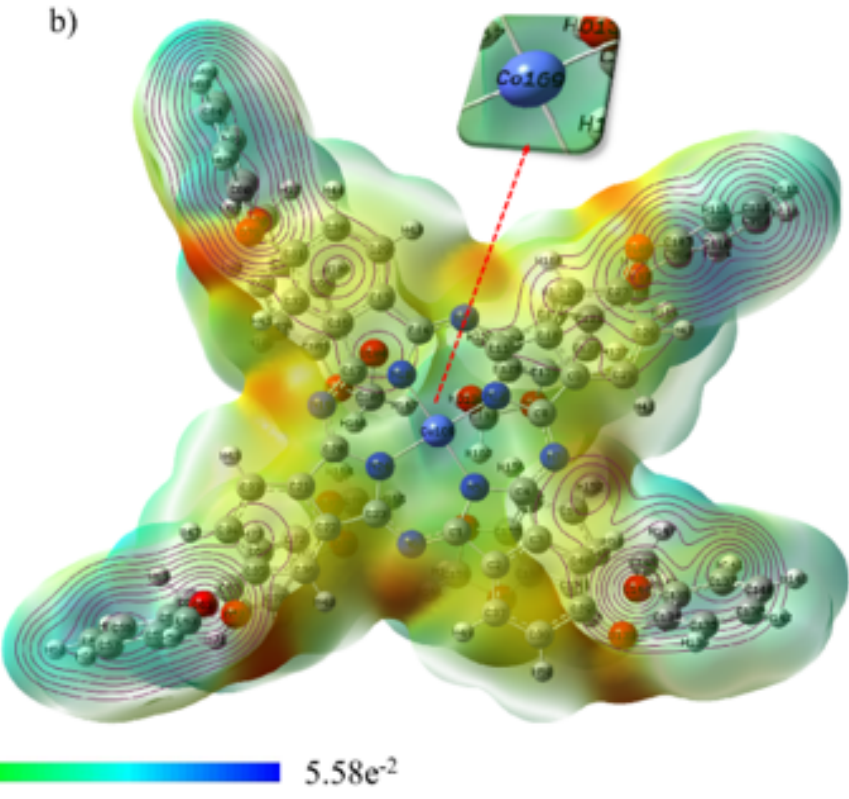

Figure 10

MEP reactive sites calculated at DFT / B3LYP methods with 6-31G, Zn-Pc (a) and Co-Pc (b), LanL2DZ basis sets.

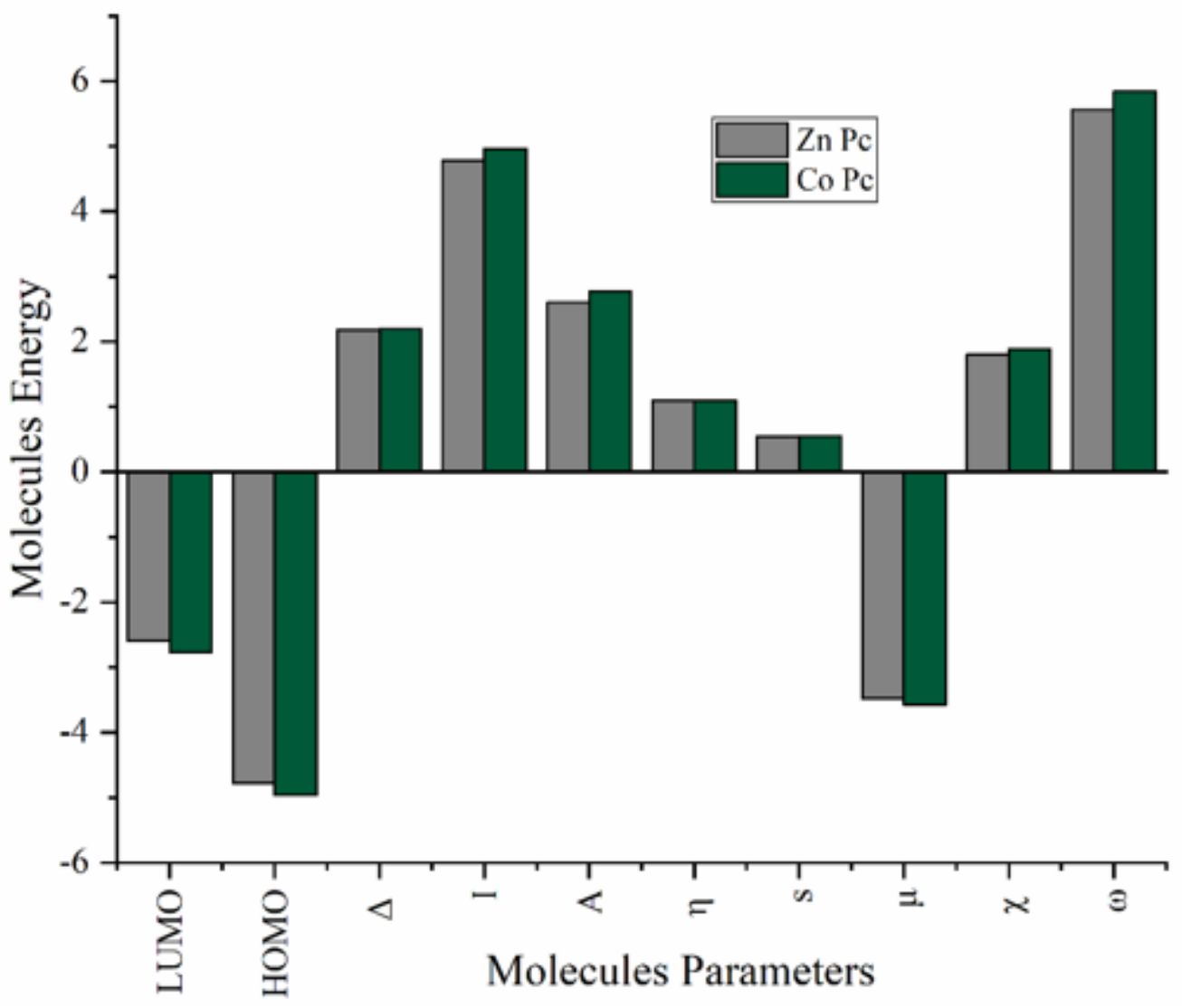




\section{Figure 11}

The correlation graphs of chemical reactivity descriptors between $\mathrm{Zn}-\mathrm{Pc}$ with 6-31G, and Co-Pc with LanL2DZ.

a)

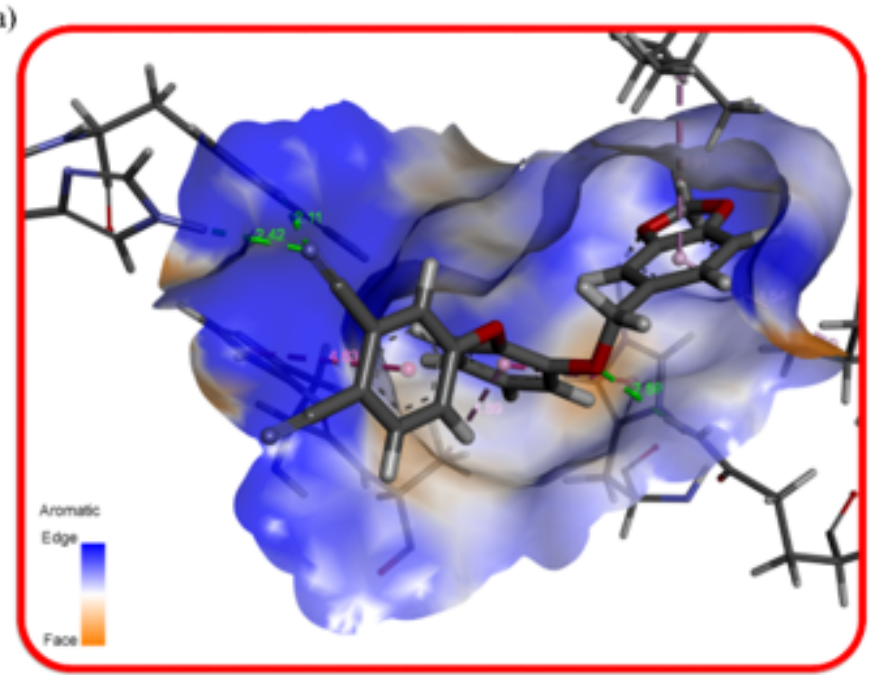

c)

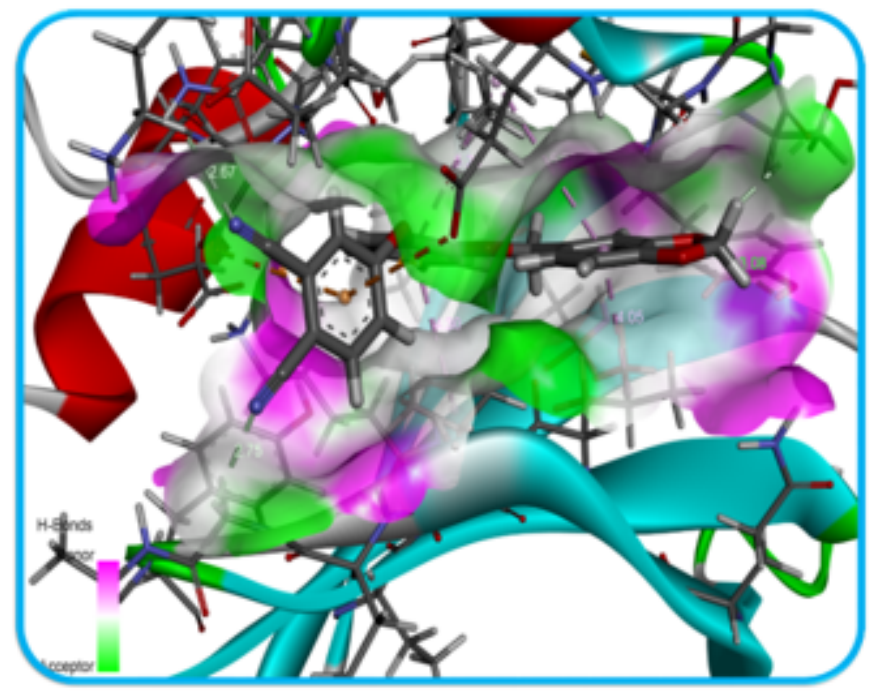

b)

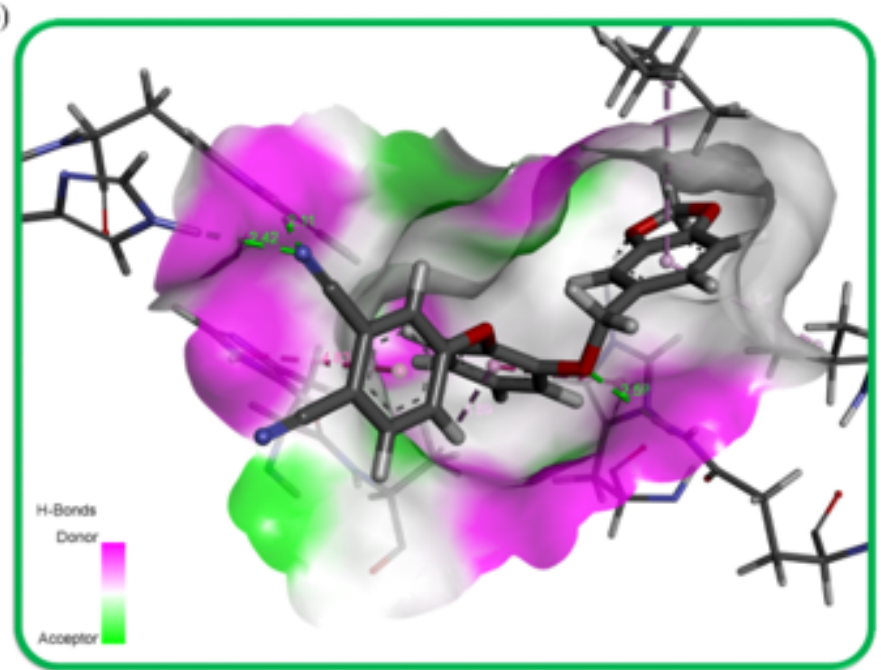

d)

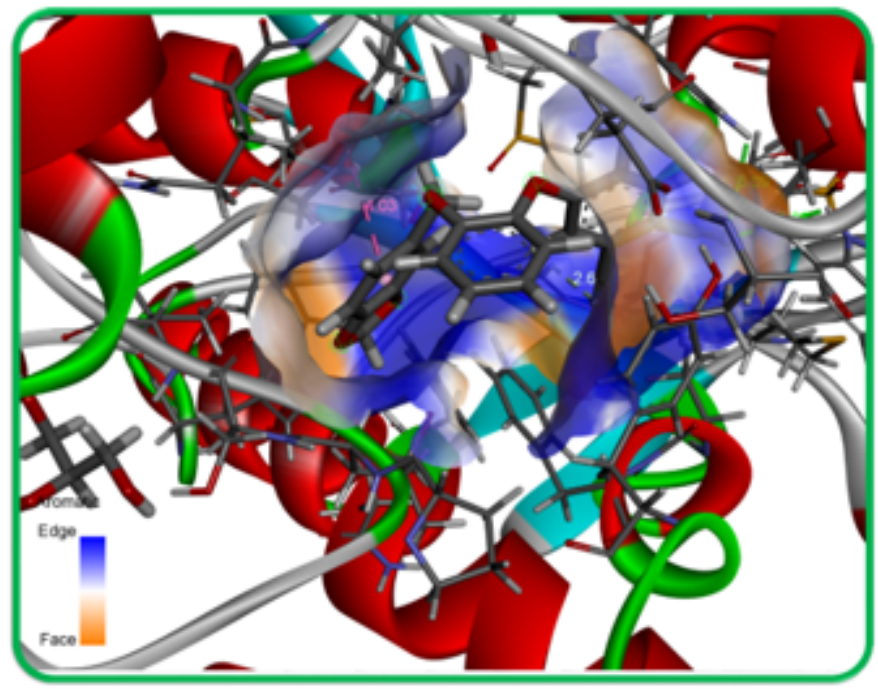

Figure 12

The interaction 3D View mode between phthalonitrile and enzymes a) the aromatic surface on the receptor of hCA I b) the hydrogen bonds donor/acceptor surface on hCA I enzyme interactions $c$ ) the hydrogen bonds donor/acceptor surface on d) the AChE enzyme interactions the aromatic surface on the receptor. 
a)

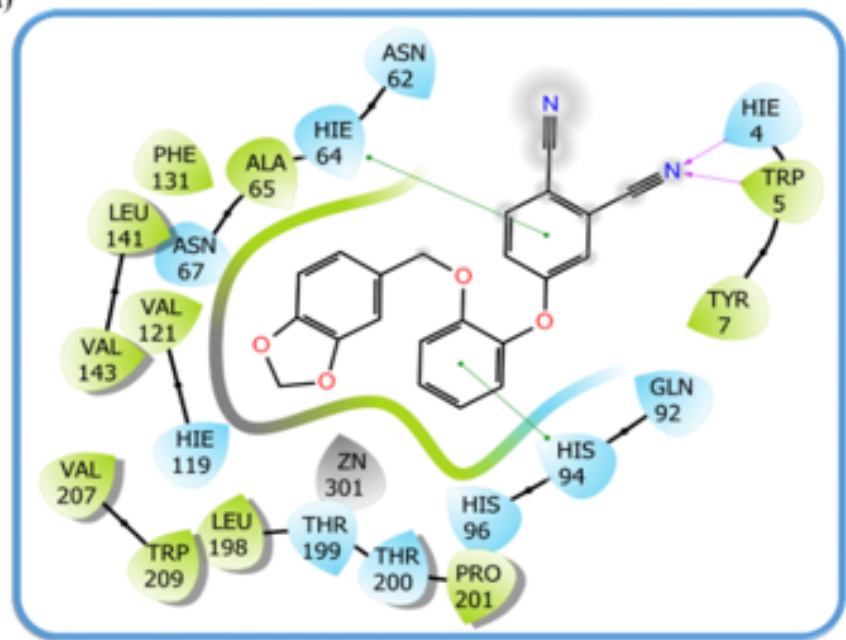

c)

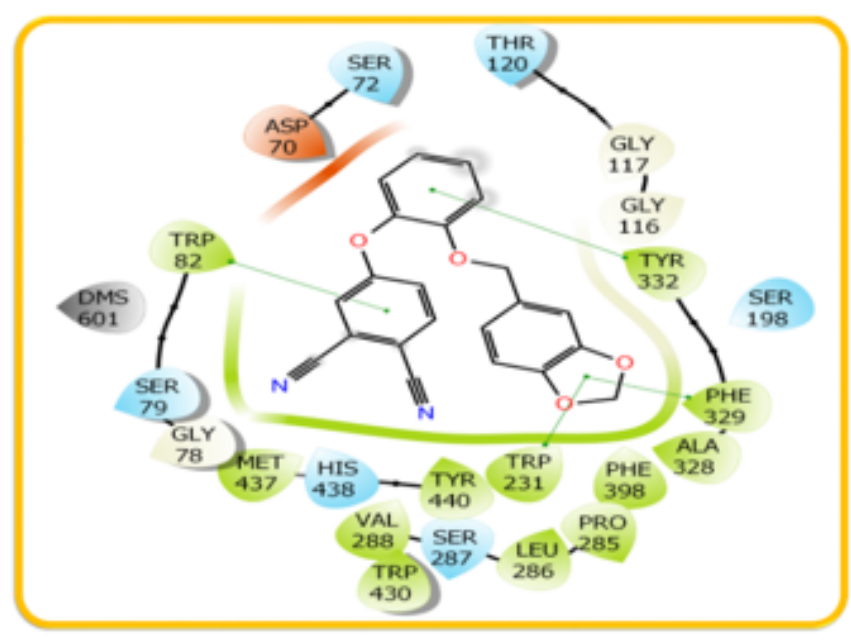

b)

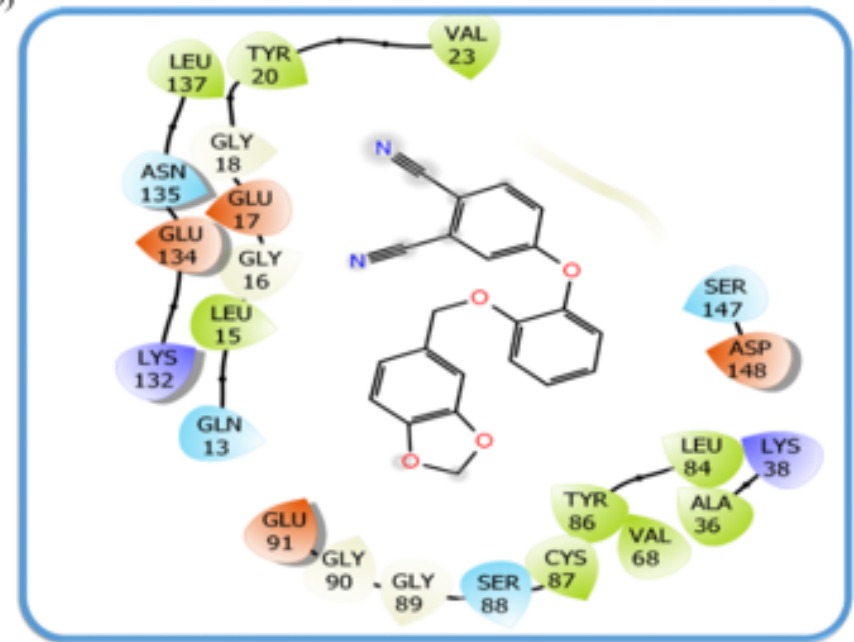

d)

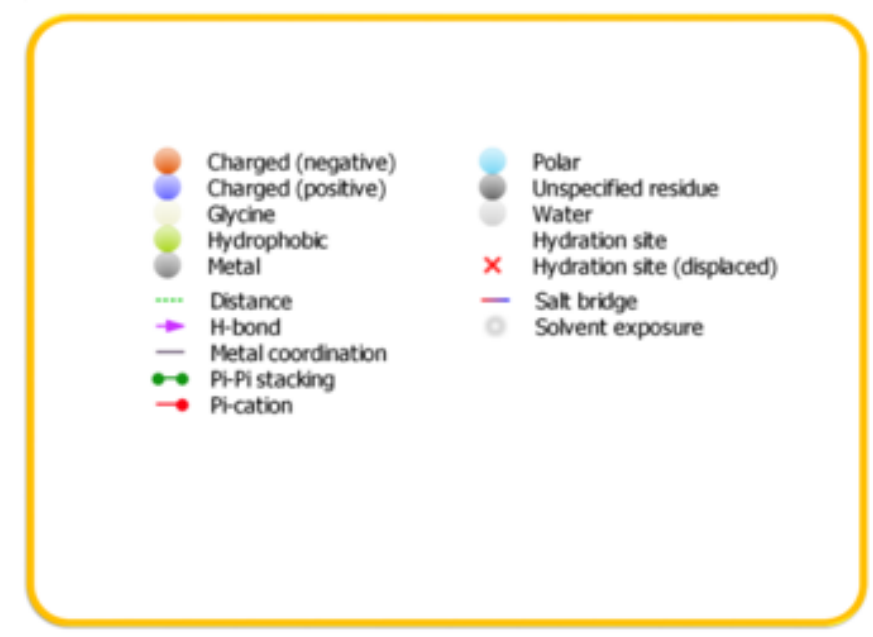

Figure 13

2D View of the interaction modes between phthalonitrile and enzymes, a) phthalonitrile -hCA II, b) phthalonitrile $-\mathrm{AChE}, \mathrm{c}$ ) phthalonitrile -BChE, d) types of interaction between molecular. 